\title{
Non-invasive multimodal imaging of Diabetic Retinopathy: A survey on treatment methods and Nanotheranostics
}

\author{
Rajkumar Sadasivam¹, Gopinath Packirisamy², Snehlata Shakya ${ }^{3}$ and Mayank Goswami ${ }^{1 凶}$ \\ 1. Divyadrishti Imaging Laboratory, Department of Physics, Indian Institute of Technology Roorkee, Roorkee, Uttarakhand-247667, India. \\ 2. Nanobiotechnology Laboratory, Department of Biotechnology, Indian Institute of Technology Roorkee, Roorkee, Uttarakhand-247667, India. \\ 3. Department of clinical physiology, Lund University, Skåne University Hospital, Skåne, Sweden. \\ $\triangle$ Corresponding author: Tel. (+91) 01332285542 (office); E-mail: mayank.goswami@ph.iitr.ac.in.
}

(C) The author(s). This is an open access article distributed under the terms of the Creative Commons Attribution License (https://creativecommons.org/licenses/by/4.0/). See http:/ /ivyspring.com/terms for full terms and conditions.

Received: 2020.11.20; Accepted: 2020.12.22; Published: 2021.01.15

\begin{abstract}
Diabetes Retinopathy (DR) is one of the most prominent microvascular complications of diabetes. It is one of the pre-eminent causes for vision impairment followed by blindness among the working-age population worldwide. The de facto cause for DR remains challenging, despite several efforts made to unveil the mechanism underlying the pathology of DR. There is quite less availability of the low cost pre-emptive theranostic imaging tools in terms of in-depth resolution, due to the multiple factors involved in the etiology of DR. This review work comprehensively explores the various reports and research works on all perspectives of diabetic retinopathy (DR), and its mechanism. It also discusses various advanced non-destructive imaging modalities, current, and future treatment approaches. Further, the application of various nanoparticle-based drug delivery strategies used for the treatment of DR are also discussed. In a nutshell, the present review work bolsters the pursuit of the development of an advanced non-invasive optical imaging modal with a nano-theranostic approach for the future diagnosis and treatment of DR and its associated ocular complications.
\end{abstract}

Key words: diabetic retinopathy, imaging biomarkers, treatment, drugs and nano-theranostics

\section{Introduction}

Diabetic retinopathy (DR) is a major complication of diabetes and one of the main causes of vision impairment and blindness among people worldwide. The prevalence of the DR is about onethird of the diabetes patients worldwide; in which one-tenth of the patients have vision impairment with increasing proportion [1,2]. It is quite essential to study DR because retina being the part of the brain which endeavor the opportunity to study the neurodegenerative and vascular changes. Besides, DR is also associated with other complications such as cardiovascular disease and stroke [3,4], nephropathy $[5,6]$, etc. Moreover, there is controversy over the vasculopathy or neuropathic nature of ocular diabetic complications. After extensive retinal neurodegenerative studies in animals, it is widely recognized that DR causes both neuropathy and vasculopathy. Researchers are still posing questions about whether neuropathy precedes vasculopathy or vice versa. The circumstantial evidence suggested the hypothesis that DR initiates with neuropathy and subsequently causes diabetic microvascular retinopathy $[7,8]$. Sohn et al. 2016 confirmed that the diabetic retinal neurodegeneration is preceded by clinical diabetic retinopathy through experiments on mouse models [9]. These findings advocated that DR is a neurodegenerative disorder that leads to the progressive disruption of various cell types of retina [10]. The neurovascular cause of DR is associated with the blood-retinal-barrier (BRB) consisting of the interdependence of neurons, glial cells, and vasculature of the central nervous system [11,12]. Also, vision impairment is closely related to glioblastoma. The worsening visual defects are one of 
the important indicator for the investigation of tumor progression in glioblastoma patients [13]. Therefore, due to the coupling and interdependence characteristic of DR complications, the early diagnosis and detection of retinopathy in the diabetic individuals is imperative for the prevention of vision loss in patients.

The present review work started with a brief note on DR and its molecular mechanism with several pathological pathways. It was followed by studying the traditional and advanced treatment methods, chemical and natural drugs, and other novel therapies for treatment of DR. Subsequently, the imaging systems play a significant role in the early diagnosis and treatment. Therefore, we also compared various optical imaging modalities with their limitations. Optical coherence tomography (OCT) is one of the preferred ocular imaging systems, is also discussed. We discussed the advantages of the above hybrid imaging system in current ocular research. The final section briefly overview the importance of nanotechnology-based carriers that can be used in DR for effective nanotherapeutic ocular drug delivery applications.

\section{Diabetic Retinopathy (DR)}

DR has been broadly classified into non-proliferative diabetic retinopathy (NPDR) and proliferative diabetic retinopathy (PDR) [14]. NPDR has been ophthalmologically characterized by intraretinal hemorrhage, microaneurysm, venous, and intraretinal microvascular abnormalities $[15,16]$. It can further lead to progressive stages such as mild, moderate, or severe NPDR, depending on the extent of the above-mentioned abnormalities. Besides, the progressive retinal ischemia and hemorrhage may lead to proliferative diabetic retinopathy (PDR). It is characterized by vitreous/pre-retinal hemorrhage and neovascularization. It also causes diabetes macular edema (DME) that leads to the leakage of blood and fluid into the retina due to the inflammation of the central retinal region. Another type of DR is the crystalline retinopathy that is associated with different genetic factors, etiology and degenerative causes. Its management approaches, imaging methods and various treatment startegies are earlier reported [17]. Besides the molecular level, the natural mechanism of the DR progression in human and animal models is the regulation of blood glucose levels that tends to the hyperglycemia (elevated blood glucose level). The mechanism of hyperglycemia is elaborated in the flowchart shown in Figure 1. In both human and animal models, the chronic hyperglycemic condition does not cause any pathological changes in its initial 5-6 weeks of existence. The cell proliferation and swelling of retinal layers, however, can be observed. Unfortunately, the retinal lesions are shown to be persisted even after the glucose level became normal and thus led to the progression of DR [18]. Therefore, it is essential to point out the role of biological phenomena that promote hyperglycemia. Besides, mitochondria, which is an important cellular organelle, that controls the energy metabolism (glucose). Its dysfunction also causes various disorders in eye, central nervous system, heart, etc. [19]. Also, the trials conducted by three different agencies demonstrated that glycemic controls play a significant role in the prevention or delay of the onset of diabetic retinopathy [20-22]. Beta cells of the pancreatic islets of Langerhans secrete insulin. This hormone is responsible for regulating the glucose level in the blood. The beta-cell dysfunction is due to several factors such as autoimmunity and inflammation, islet amyloid, lipotoxicity, adipokines, insulin resistance. The beta-cell dysfunction in type I diabetes is due to the autoimmunity of the T cells. The T cells attack beta cells causing approximately 70-90\% loss. Whereas in type II, the dysfunction is complex and varies from asymptotic to symptoms of hyperglycemia. Apparently, both types substantially overlap and difficult to differentiate. Henceforth, the assessment of beta-cell mass and function is vital to understand the mechanism of the pathogenesis of diabetes and all its clinical complications that includes DR. Direct evaluation methods are thus not available. There are however various simple methods, and development of markers for the proper evaluation. These methods are important for understanding the pathogenic mechanism involved in the disease progression in animal models and human [23]. Figure 1 summarizes the continuous flow diagram of all key factors involved in the pathogenesis of diabetic retinopathy (DR) and associated clinical complications.

\section{Molecular mechanism of DR}

In terms of its etiology and pathology, DR has enormous similarities with other neovascular diseases having chronic inflammation such as infiltration of immune cells, macular edema, vascular permeability, tissue destruction, and abnormalities in neovascularization. The primary risk factor for the development of DR is diabetes, in which Type I diabetes is more severe than type II that leads to vision loss. The other high-risk factors of DR are smoking, race, hyperlipidemia or dyslipidemia (excess fatty deposits in the blood), hyperglycemia, and hypertension (high blood pressure), etc. [24,25]. The major pathological factors of DR include inflammation [26,27], up-regulated intercellular 
adhesion molecule-I (ICAM-1), enhanced leukostasis inside the retinal vessels [28], elevated vascular endothelial growth factor (VEGF) agents promotes reduced tight-junction proteins which leads to breaking of BRB [29], increased nitrous oxide synthase (NOS) [30] and inorganic phosphate's imbalanced metabolism [31]. Several interconnected biochemical pathways play a significant role in the development of DR, such as increased hexosamine biosynthesis pathway (HBP), polyol pathways, the formation of advanced glycation end products (AGE), hemodynamic variations, and activated Protein kinase $\mathrm{C}$ (PKC) [32-34]. Microvascular endothelial dysfunction is due to the RhoA/mDia-1 and RhoA/ROCK1 pathways in which RhoA act as GTPase. Activation of these pathways leads to initiated various pathological agents such as VEGF, insulin like growth factor (IGF), renin-angiotensin-aldosterone system (RAAS), occlusion of the capillary [28], increased ER and oxidative stress. Further, it was followed by de-regulation and autophagy [35], RPE dysfunction, epigenetic variations such as disruption in gene transcription, methylation of DNA and regulated non-coded RNAs $[36,37,37,38]$. Interestingly, the depletion of transforming growth factor- $\beta$ (TGF- $\beta$ ) signaling results in changes in the structure and function of the retina that mimics the characteristics of DR. Inhibition of gene functions like BMP2 (bone morphogenic protein 2) and Toll-like receptor 2 (TLR2) is also implicated in DR [39]. The formation of plasma membrane pores activates the $\mathrm{P} 2 \mathrm{X7}$ receptor of the ligand gated ion channels leads to the development of DR through induced inflammation [40]. Recent studies found that the high glucose (HG) and thioredoxin interacting proteins (TXNIP) were up-regulated in the retinal cells. In general, TXNIP overexpression causes severe pathological complications such as mitochondrial dysfunction, ROS stress, inflammation and premature cell necrosis due to the suppression of antioxidant property and thiol reducing ability of thioredoxin [41]. Furthermore, hyperglycemia-mediated vascular dysfunction and the following tissue breakdown occurs through four main routes. 1) Elevated polyol pathway flux, i.e. increase in $\mathrm{NADH}^{+} / \mathrm{NAD}$ ratio via sorbitol pathway leads to the decrease in cytosolic NADPH and other cellular functions which leads to the cytosolic redox imbalance. 2) Increased AGE formations and glycosylation of proteins promotes alteration in the gene expression and induces the inflammatory cytokines. 3) Development of VEGF and other multiple growth factors due to the activation of PKC through diacylglycerol (DAG) and AGEs formation with intermediate ROS generation. Variation in the gene expression and protein function is attributed to the increased hexosamine flux occurs through conversion of fructose 6 phosphate to uridine diphosphate $N$ - acetyl glucosamine. However, these major four metabolic pathways shown in Figure 2 are interlinked through the production of superoxide and elevated reactive oxygen species (ROS) generation which forms the platform for developing potential treatment strategy $[42,43]$.

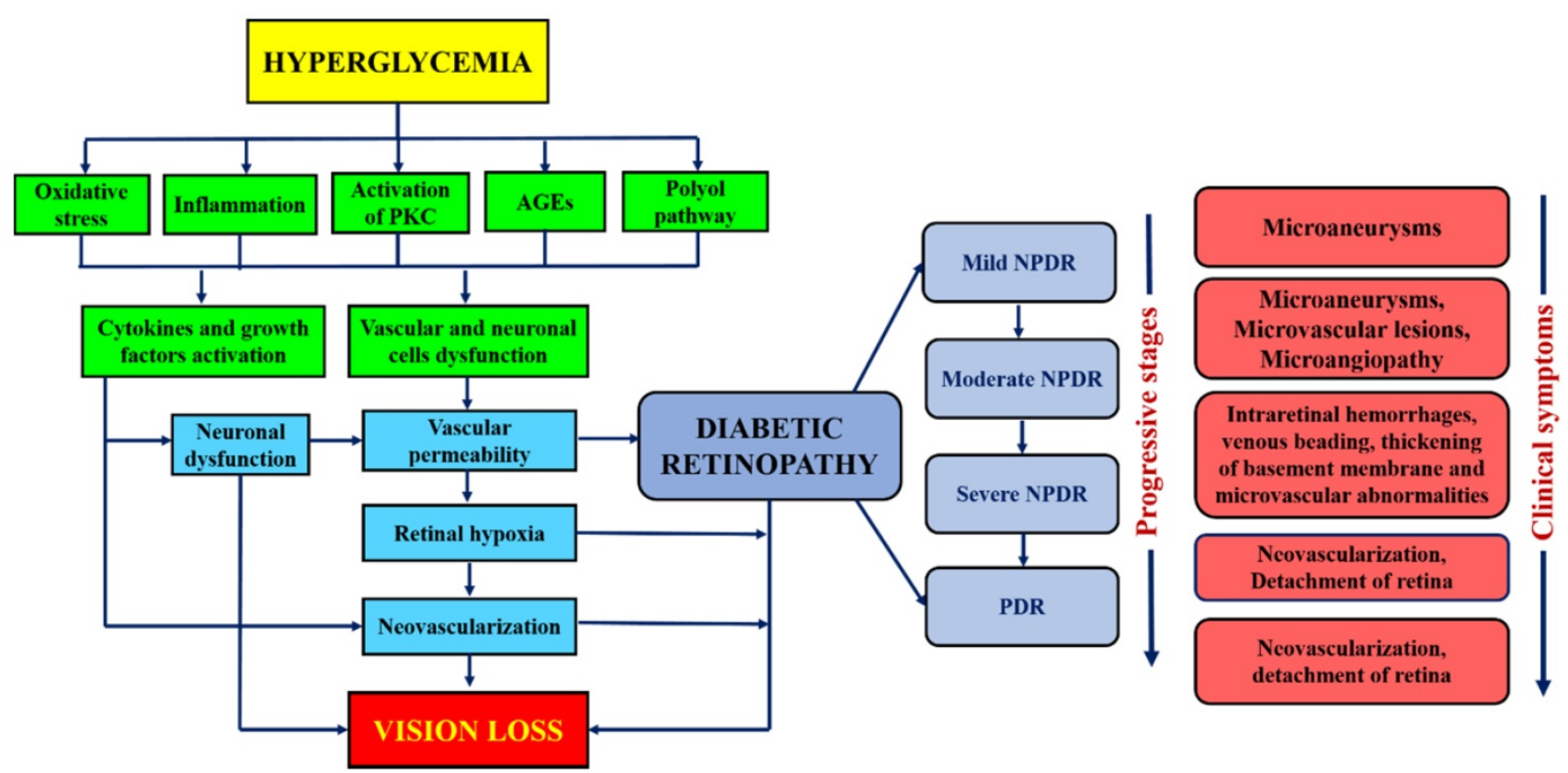

Figure 1. Flow diagram showing the major physiological factors involved in the pathogenesis and clinical symptoms at different stages of DR. 


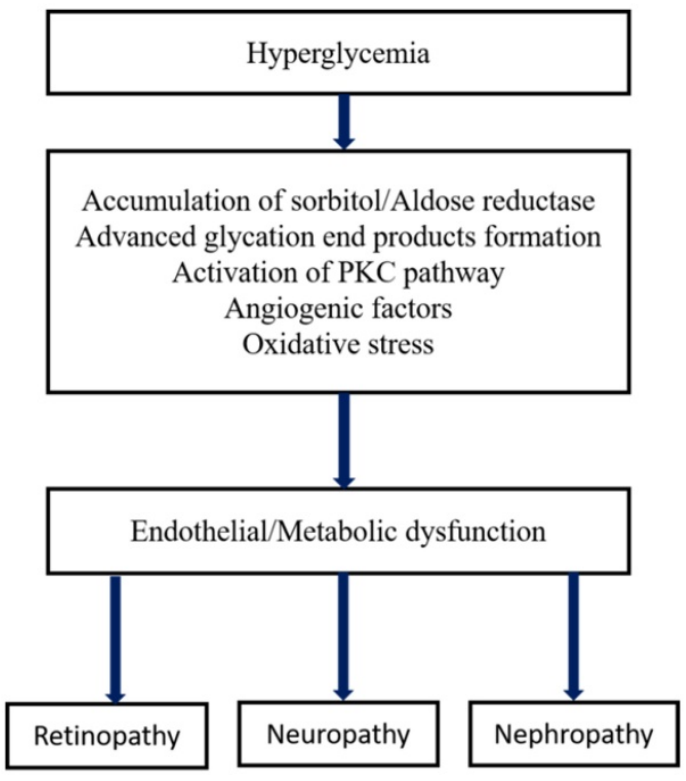

Figure 2. Metabolic pathways of diabetic microvascular complications [162]

In clinical development, the success rate of several new promising drug candidates in human clinical trials remains lower. Such decline is due to the entry of a large number of drug interactions with less validated targets, lack of efficacy in intermediate stages of clinical studies. These intricacies can be improved by having stringent criteria during the non-clinical stages of the development of drugs and diagnostic tools. A prominent success in clinical trials would be achieved only through the animal models, which assists in the evaluation of target validation and efficacy of the drug candidates. Direct evaluation/testing of a newly developed compound for a specific human disease through human models will be a challenge to the human race. Therefore the selection of lower species from the animal hierarchy (non-human animal models), preferably mice, rats, rabbits, etc. would be scientifically valid complying with the animal ethical standards.

\section{Treatment}

Several biomedical devices have been used for the detection, diagnosis, and treatment. Albeit the prevalence of advanced treatment techniques, the DR patients are having combined treatment options such as systemic monitoring of blood pressure and glucose level, laser-based photocoagulation, surgery, steroidal, and anti-VEGF intravitreal injections [44]. Confocal laser scanning microscope, fluorescence angiography, ultrasound, and optical coherence tomography (OCT) are a few examples of biomedical imaging systems used for diagnosis. The imbalanced glycemic control can lead to the progression of clinical signs for DR and causes vision-impairing complications irrespective of intensive hypoglycemic treatment [45]. Panretinal photocoagulation (PRP) is the common treatment method used to prevent progressive visual impairment in DR patients with high-risk characteristics for PDR. Denaturation of tissue proteins that causes the coagulation or the cell necrosis is thermally burned by argon laser to subdues the PDR symptoms. However, PRP is a relatively harmful treatment technique where it sacrifices the outer retinal layers such as retinal pigment epithelium (RPE), inner plexiform layer (IPL), and nerve fiber layer (NFL) in order to save the central vision [46]. Consequently, focal photocoagulation slows down the frequency of persistent DME by blocking the fluid leakages in respective patients [47]. Also, the laser photocoagulation, despite having the preventive potential for the progressive complications of DR, it addresses the pathological effects. Intravitreal injection, an invasive treatment method, involves the infusion of therapeutic agents such as anti-VEGF and steroids. Intravitreal administration of triamcinolone acetate (IVTA) gives the short-term benefits in comparison to the focal photocoagulation procedure in DME patients [47]. Intravitreal administration of anti-VEGF agents such as pegaptanib, ranibizumab, bevacizumab, and aflibercept have a positive impact on vision by annihilating the age-related macular degeneration (AMD) caused due to choroidal neovascularization [48]. These drugs exhibit significant efficacy by suppressing DME and restore the vision loss in the case of diabetic retinopathy (DR) [49-51]. The chronic and relapsing characteristic of DME requires multiple successive intravitreal injections round the year. Also, the inhibition of VEGF agents activates the pathologic angiogenesis simultaneously, which are the trophological factors for the neuronal and endothelial cells $[52,53]$. Henceforth, a non-invasive therapeutic tool has to be developed for the treatment of DR [54]. Alongside, in order to protect ourselves from DR and minimize its potential complications, bio-imaging based theranostic approaches have to be developed with appropriate animal models before the clinical trials. Therefore we will be discussing the noninvasive imaging techniques in the later section.

\section{Treatment planning}

The ophthalmologists and engineers worldwide are working towards achieving the theranostic objectives in order to overcome the current treatment limitations. The primary goal is the rehabilitation of the functional integrity of neovascular and BRB units [55]. Various types of cells and their interactions between neurons, glial cells, and secretory mediators are involved in the neovascular units. When DR 
progresses with time, alteration of cellular interactions takes place with inflation in inflammatory cytokines and VEGF growth factors. Accordingly, an evaluation of the specific functions of various types of cells and mediators in DR promotes the development of pathogenesis mediated therapeutic procedures in DME. DR also causes retinal neovascularization or angiogenesis having characteristic changes that lead to the progression of new vessels along with the components of the vitreous cavity [56]. In order to treat and avoid complications such as vitreous hemorrhage $(\mathrm{VH})$, tractional retinal detachment (TRD), etc. due to retinal neovascularization, antiVEGF agents can be used by targeting the synergy among the endothelial cells and vitreous proteins in specific [57].

\section{Treatment methods of DR}

Various treatment methods of DR include laser photocoagulation (LP), injections of steroids, anti-VEGF agents through the intravenous route, and intraretinal surgery. The treatment options for DR are limited after the visible threats are observed in patients. Table 1 represented few conventional and new laser based treatment approaches with benefits and their adverse effects. LP is a surgical technique that suppresses the progression of DR, and vitrectomy helps in the prevention of vision loss from the advanced stages of DR. Vitrectomy is a conventional surgical procedure carried out for vitreous haemmorhage in retinopathic patients. Some of the complexities are vitreous removal, peeling of membrane, cataract, recurrent hemorrhage and neovascular glaucoma [58]. This minimal invasive surgical technique got faded due to the advancements in intravitreal therapies using anti-VEGF agents. The main objective of LP is to reduce vascular leakage using the focal and grid laser burns in the BRB region. Macular focal laser photocoagulation is attributed to the DME, whereas the grid-based laser photocoagulation leads to the high-risk PDR [59-62]. However, both these methods possess the disadvantage of additional vision loss. Also, a study reported that the focal/grid laser application to the central retina diminishes the prevailing vision rate by $50 \%$ in DME individuals $[61,63]$.

In modern era, the dominancy of the intravitreous anti-VEGF injections demonstrated the therapeutic advancements in DR [64-66]. Recent experiments suggested that the anti-VEGF agents include bevacizumab, aflibercept, and ranibizumab are found to be effective in the treatment of DR in terms of vision improvement $[67,68]$. The anti-VEGF therapy is effective for retinal neovascularization with PDR, where it transforms the severe condition to the less developed state, and it is a viable alternative to PRP treatment [69]. Also, the eyes treated with ant-VEGF agents shows better visual acuity in comparison to the PRP [70]. The evidence for the treatment outcomes of the anti-VEGF therapy against neovascular AMD was reported in extent [71]. The other advantages of anti-VEGF therapy are decreased rate of onset DME, less vision field loss, and reduced vitrectomies over time. Table 2 listed some of the essential anti-VEGF and anti-inflammatory drugs with advantages and their adverse effects. Diabetic Retinopathy Clinical Research Network (DRCR.net) evaluated the combinatorial impact of LaserRanibizumab-Triamcinolone in Diabetic Macular Edema (DME) and shown 50\% positive outcomes in comparison to the alone focal/grid laser treatment. Both laser and anti-VEGF intravitreal injections, apart from its significant effects, had several adverse effects retinal damage, scar formation [72], endophthalmitis [73], intraocular inflammation [74], increase in intraocular pressure (IOP) [75]. The vitreoretinal steroidal injection causes cataract development and enhanced intraocular pressure [76]. The adverse side effects of these agents are caused both by the drug itself and its intravitreal route of administration and other local side effects are macular hole, uveitis etc. [77]. All the treatment procedures are available only to the advanced stages of DR and were performed to prevent future vision loss; however, the retinal damage done is unavoidable [78].

Table 1. Laser treatment methods of DR

\begin{tabular}{|c|c|c|c|c|}
\hline Type & Drugs & DR treatment status & Benefits & Adverse effects \\
\hline \multirow[t]{2}{*}{$\begin{array}{l}\text { Conventional laser } \\
\text { treatment }\end{array}$} & $\begin{array}{l}\text { Focal/grid laser } \\
\text { [61] }\end{array}$ & Adjuvant treatment for DME & $\begin{array}{l}\text { Reduce the risk of moderate visual loss, increases the chance } \\
\text { of visual improvement, decreases the frequency of persistent } \\
\text { macular edema (Early Treatment Diabetes Retinopathy } \\
\text { Study (ETDRS)) }\end{array}$ & $\begin{array}{l}\text { Visual acuity loss; visual } \\
\text { field loss }\end{array}$ \\
\hline & PRP [164] & $\begin{array}{l}\text { Adjuvant treatment for PDR } \\
\text { with high-risk complications }\end{array}$ & $\begin{array}{l}\text { Reduce the rate of severe visual loss in PDR and inhibit the } \\
\text { progression of retinopathy (Diabetic Retinopathy Study } \\
\text { (DRS)) }\end{array}$ & $\begin{array}{l}\text { Visual acuity loss; } b \text {. } \\
\text { Constriction of peripheral } \\
\text { visual field }\end{array}$ \\
\hline \multirow{3}{*}{$\begin{array}{l}\text { New laser } \\
\text { approaches }\end{array}$} & PASCAL [165] & Under clinical evaluation & Accurate control of the laser; less treatment time & - \\
\hline & D-MPL [166] & Under clinical evaluation & Collateral damage is minimal & - \\
\hline & NAVILAS [167] & Under clinical evaluation & High accuracy of laser spots & - \\
\hline
\end{tabular}


Table 2. Anti-VEGF and Anti-inflammatory drugs for Treatment of DR

\begin{tabular}{|c|c|c|c|}
\hline Classification & Drugs & Benefits & Adverse effects \\
\hline \multirow[t]{4}{*}{$\begin{array}{l}\text { Anti-VEGF } \\
\text { drugs }\end{array}$} & $\begin{array}{l}\text { Ranimizumab (Lucentis) [168,169] (FDA } \\
\text { approved) }\end{array}$ & $\begin{array}{l}\text { a) Huge BCVA improvement and high reduction in } \\
\text { CRT over laser treatment for DME. } \\
\text { b) Non-inferior to PRP in the treatment for PDR for } 2 \\
\text { years }\end{array}$ & $\begin{array}{l}\text { Vitreous hemorrhage; increased } \\
\text { intraocular pressure (IOP) inflammation } \\
{[170] .}\end{array}$ \\
\hline & Pegaptanib (Macugen) [171] (FDA approved) & BCVA improvement, in DME patients & Increased IOP; conjunctival hemorrhage \\
\hline & Aflibercept (EYELEA) [65] (FDA approved) & High reduction in CRT and better visual acuity & $\begin{array}{l}\text { Increased IOP; vitreous hemorrhage } \\
\text { inflammation [170]. }\end{array}$ \\
\hline & Bevacizumab (Avastin) [170] (FDA Approved) & $\begin{array}{l}\text { BCVA improvement and reduction in CRT in DME } \\
\text { patients }\end{array}$ & $\begin{array}{l}\text { Tractional retinal detachment (TRD); } \\
\text { vitreous hemorrhage; increased IOP; } \\
\text { inflammation. }\end{array}$ \\
\hline Non-specific & Squalamine [172] & - & - \\
\hline \multirow[t]{3}{*}{$\begin{array}{l}\text { Anti-angiogeni } \\
\text { c drugs }\end{array}$} & Razuprotafib AKB-9778 [173] (Phase II trial ) & $\begin{array}{l}\text { Reduction in CRT in combined use over the } \\
\text { Ranibizumab alone therapy }\end{array}$ & $\begin{array}{l}\text { Worsen diabetic retinal edema; } \\
\text { reduction in visual acuity }\end{array}$ \\
\hline & Nesvacumab (Phase II clinical trial) & $\begin{array}{l}\text { No differentiation in combined and Alflibercept alone } \\
\text { therapy }\end{array}$ & No new safety indications observed \\
\hline & Faricimab (Phase III clinical trial) & $\begin{array}{l}\text { BCVA improvement and CRT reduction over } \\
\text { Ranimizumab in DME patients }\end{array}$ & No new safety indications observed \\
\hline \multirow[t]{3}{*}{$\begin{array}{l}\text { Intravitreal } \\
\text { steroids }\end{array}$} & Triamcinolone [64] (FDA approved) & $\begin{array}{l}\text { Huge improvement in Triamcinolone + laser group } \\
\text { over the control in pseudophakic eyes }\end{array}$ & $\begin{array}{l}\text { Cataract surgery; high intraocular } \\
\text { pressure (IOP); vitreous hemorrhage. }\end{array}$ \\
\hline & Ozurdex [174,175] (FDA approved) & $\begin{array}{l}\text { BCVA improvement, reduction in CRT in DME } \\
\text { patients }\end{array}$ & $\begin{array}{l}\text { Cataract; increased IOP; vitreous } \\
\text { hemorrhage. }\end{array}$ \\
\hline & Iluvein [176] (Clinically approved implant) & BCVA improvement in DME patients & $\begin{array}{l}\text { Cataract; increased IOP; vitreous } \\
\text { hemorrhage. }\end{array}$ \\
\hline
\end{tabular}

BCVA: best corrected visual activity, FDA: Food and Drug Administration, U.S.A.

Table 3. Natural therapeutic compounds for treatment of DR

\begin{tabular}{lll}
\hline Plants $\left({ }^{*}\right)$ & Active part and compound & Study \\
\hline Allium cepa [177]; Allium sativum [178]; Catharanthu roseus and & Bulb, Alkyldisulfides; Bulb, Alkyldifulfides; Leaf, & Diabetic rabbits; healthy rabbits; healthy \\
Coccinia indica [179]; Cyamopsis tetragonolobus [180]; Ficus & Alkaloids; Seed and pod, Alkaloids; Stem bark, & rats; diabetic animals; diabetic rodents; \\
bengalensis [181]; Momordica charantia [182-184]; Trigonella & Alkaloids; Aerial, glycosides; Seeds, Trigonelline & NIDDM patients; IDDM and NIDDM \\
foenumgraecum [185] & & patients
\end{tabular}

*Clinically not approved.

\section{Natural compounds in treatment of DR}

Several research works reported that the natural compounds always show promising effects against DR. Oral administration of curcumin suppresses the expression of VEGF in the retina of diabetic rats [79]. Few herbal compounds play a significant role in diabetes, having hypoglycemic effect and prevents the secondary complications of DR owing to their high antioxidant properties. Some of the herbal drugs are Turmeric (Curcuma Longa), Fenugreek (Trigonella foenum-graecum), Tulsi (Ocimum sanctum), Guduchi Tinospora cordifolia etc. Besides, there are several natural plants having hypoglycemic properties are shown in Table 3. The major advantage is that so far no adverse effects from the plants has been reported which is a safe naturally derived compounds for the management of diabetes. These natural compounds are not clinically approved hence there is no significant clinical evidence in the treatment of DR so far.

\section{Other treatment strategies for DR}

There are several inhibitors such as fibrates, statins, thiazolidinediones, PKC $\beta$, ALR2 etc. are used in the treatment of DR and other complications.
Fenofibrate Intervention and Event lowering in Diabetes (FIELD) study reported that the long-term treatment of fenofibrate reduces the progressive stages of DR and avoids the necessity for laser treatment through. Early treatment diabetic retinopathy study (ETDRS) using candesartan controls the progressive stages of DR in type I and II diabetes [80]. Statins are profound to be effective in controlling the promotion of retinal inflammatory factors, and cytokines such as VEGF, ICAM's in diabetic eyes. Animal studies reported that both Lovastatin and Simvastatin were involved in the inhibition of pro-inflammatory transcription factor NF-KB and also inhibits the expression of VEGF and VEGF induced intercellular adhesion molecule. Thiazolidinediones are insulin-sensitized peroxisome proliferator-activated receptor PPAR- $\gamma$ agonists, commonly known as Glitazones. Its anti-inflammatory action decreases the fatty acids in plasma that have a significant effect on the vasculature, which makes it suitable for the treatment of DR. Few examples of thiazolidinediones available in India are rosiglitazone, pioglitazone, etc. Several synthetic and natural orally active drugs are used for the inhibition of PKC $\beta$ regulators for controlling the 
microvascular complications in diabetes. Midostaurin is naturally available alkaloid staurosporine, which inhibits the kinases of PKC. The animal studies reported its inhibitory action against neovascularization. However, shown hepatotoxicity due to the non-specificity of the drug [81]. Similarly, Ruboxistaurin is an orally active protein kinase $\beta$ inhibitor used for the treatment of microvascular complications of DR. It also had a mild effect on DME, and the outcome of the clinical trials (random) shown the functional visual improvement and $50 \%$ of DR can be prevented $[82,83]$. It has to be noted that the above conclusions are derived from clinical and animal experimental studies, hence these inhibitors are not clinically approved for treatment. Apart from this, there are several advanced methods such as stem cell therapy, gene therapy, and other regulating factors for controlling the ocular complications are still in the research levels which are being reported by various research works [84-86].

An integrated approach is necessary for the reduction of mortality rate due to DR[87]. Development of effective treatment strategy is essential for early prevention of visual impairment and show constant improvement in the vision. Henceforth, the clinical researchers are putting persistent efforts in pursuit of answers for the undisclosed mystery involved in DR treatment and its complications. A suitable example is that $40-50 \%$ of cases with DME do not respond to anti-VEGF therapy. This kind of therapeutic gap necessitates the clinical engineers to develop advanced state of the art theranostic systems based on non-invasive, nondestructive treatment methods, which will be the future platform for clinicians.

\section{Imaging Biomarkers}

Eye is one of the appropriate candidates for being the optical window for the investigation of ocular abnormalities in small animal models and its associated neurodegenerative complications and tumor as well. These studies are to be carried out through non-invasive imaging tools without the need for any biopsy. These imaging techniques become the privilege for either human or animal models, which is ethically safe and can be studied until the natural decease of the animals.

Over the decade, the development of various advanced imaging modalities made it possible for the routine imaging of human retina in vivo at subcellular resolution [88]. Ophthalmic imaging is still been used in small animals for translational research. Various imaging modalities such as optical imaging, radionuclide imaging, magnetic resonance imaging, computed tomography, ultrasonography, etc. are used in ophthalmology and other applications [89]. The non-invasive imaging and optical modalities such as bioluminescence, reflectance, magnetic resonance spectroscopy imaging (MRSI), positron emission tomography (PET), and contrast-enhanced perfusion MRI have their intrinsic limitations for the investigation of ocular and tumor-related neovascularization [90-95]. The human eye, by nature, promotes the sub-cellular mediated resolution and non-invasive in vivo imaging of the retina and its vascularization in healthy and diseased states (retinal tumor, DR, uveitis, etc.). It has its in-built natural vision with imaging optics, cornea, and the crystalline lens $[88,96,97]$. In vivo imaging of mouse retina using computed tomography based adaptive optics (AO) enhanced OCT/SLO system has also been reported recently [98-101]. Imaging of the retinal layers using the advanced techniques is challenging due to the non-availability of the sophisticated non-invasive system where the retinal size animal models is ten-fold smaller than that of humans. Also, there are very limited in vivo ocular non-invasive imaging methods available for retinopathy with in depth resolution [102-107]. Recently, an early detection of DR using a non-mydriatic, full field electroretinopathy, easy to operate devise was reported. This devise is used as an adjunctive tool for the screening of DR [108]. Similarly, there are several computer aided diagnosis of DR has been reported $[109,110]$. OCT based imaging and diagnosis of DR in animal models are limited.

Optical coherence tomography (OCT) is a retinal imaging tool that uses coherent infrared laser by analyzing the reflectance properties of a sample with in-depth resolution. In short, OCT rapidly procreated the volumetric representation of the intrinsic retinal layers and vasculature in three-dimensional resolutions of few micrometers. Some of the uncommon features of AMD in eyes such as retinal tabulation, cystoid degeneration and choroidal cavern were also reported through OCT [111]. In contrast, the scanning laser ophthalmoscopy (SLO) rendered the confocal reflectance and fluorescence images [112-114]. The systematic digital photograph of such an hybrid OCT/SLO imaging system of our research group was represented in Figure 3. The research work has reported the potential of this combined OCT/SLO system. Figure 4(A-J) shows the angiography of retina and choroid through green fluorescing fluorescein and micellar nanoparticle tagged with red fluorescing rhodamine-X. Comprehensively, a combined OCT/SLO system comprises AO-SLO for imaging physiological events of retinal components such as blood flow, microglia cells, capillaries, GFP expression of cone photoreceptor cells and its 
three-dimensional localization by combining with the widefield OCT/pv-OCT and SLO records. Similarly, Optical coherence tomography angiography (OCTA) is an innovative utilization of OCT for the visualization of retinal layers without use of dyes [115]. It has several features such as increased acquisition speed and image information over the dye based angiographic system [116].

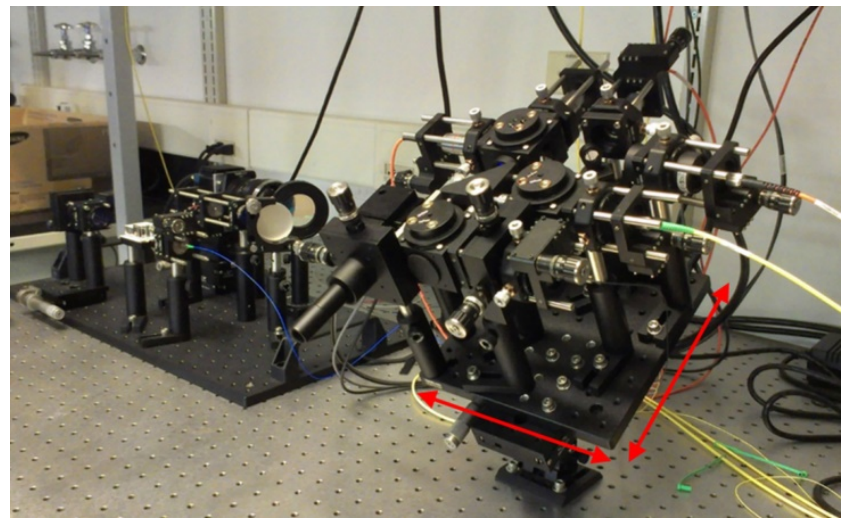

Figure 3. Digital photograph of combined OCT/SLO imaging system.

The advantages of these two systems have been complied with the natural optical systems like in mouse eye, amalgamating their capabilities, and promotes in vivo mouse studies for probing the structural and functional information of the retinal unit $[117,118]$. The utilization of such fusion adaptive optics (AO) for imaging is an ongoing revolution in bio-imaging research in which structural and functional visualization of cells can be done in vivo through the genetically encoded optical probes[119]. AO-SLO is one of the most appropriate imaging biomarkers used in recent times designed exquisitely for the fluorescence and reflectance imaging of the retina of the mouse [101]. The utility of this imaging system could be demonstrated for the imaging of retinal capillaries, microglia, retinal blood flow, and cone photoreceptor cells, which collectively exhibit green fluorescence protein (GFP). This further illustrates the localization and visualization of the morphological structures and cells in 3D by combining the AO-SLO data with wide field OCT/phase variance OCT and SLO data. The studies performed on such a combined imaging system reported the extensive differentiation and visualization of microvascular retinal layers, choriocapillaris represented in Figure 5 and Figure 6, respectively.

In general, the custom OCT system comprises of a superluminescent diode as light source, a spectrometer with a diffraction grating, an imaging objective, CMOS camera with an operational range up to $100,000 \mathrm{~A}$-scan/s as its detector. It also consists of a sample arm with fiber collimator lens, galvanometric scanners and achromatic lens, reference arm consist of fiber collimator lens, neutral density filter, achromatic lens, a static silver coated mirror and dispersioncompensating block. Theoretically, the OCT system has the axial and lateral resolution $(\sim 2 \mu \mathrm{m}$ and $\sim 5 \mu \mathrm{m})$ having image acquisition of a visual angle over 41 degrees $(\sim 1.4 \mathrm{~mm})$ [120]. Similarly, a custom-made SLO multichannel system is used for the acquisition of reflectance and fluorescence images. It possesses an essential feature of the spectrum analyzer for the fingerprinting of autofluorescence and fluorescent cells through spectral emission. The images were combined with the OCT retinal vasculature data, followed by the localization of fluorescent cells and retinal microvasculature events in higher resolution in
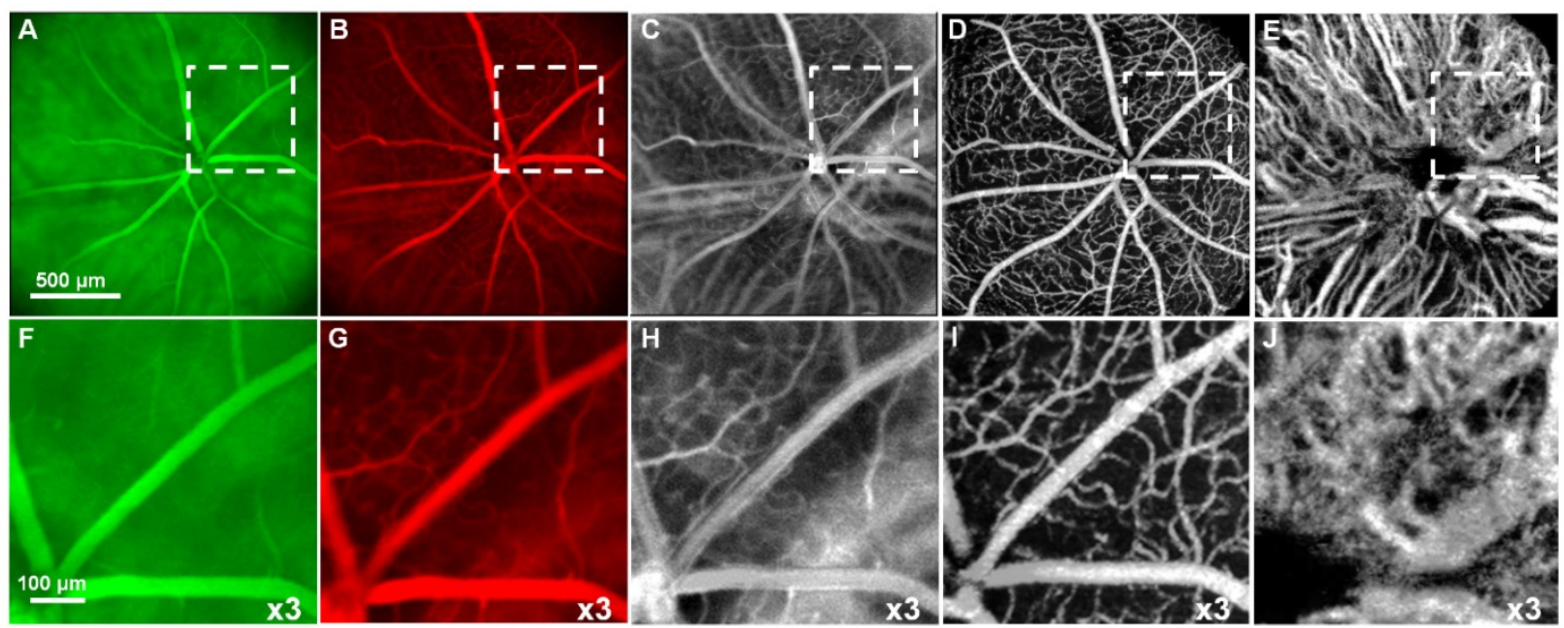

Figure 4. Simultaneous SLO and OCT imaging of a nude mouse with two fluorescence channels injected with fluorescein and nanoparticles tagged with rhodamine-X: (A) Image of "green" ("GFP") fluorescence channel; (B) Image of "red" fluorescence channel; (C) Image of the ratio between (B) and (A); D Image of the retinal vasculature extracted from OCT (Pv-OCT); (E) Image of the choroidal vasculature obtained from OCT. (F-J) x3 magnified images of the white dashed area from Figure 4A-E respectively showing enhanced visualization of chorioretinal vasculature. (Adapted from Goswami et al. 2016 [163]) 
AO-SLO imaging [121]. A general method was developed using the pv-OCT and AO-SLO system for the localization and characterizing the retinal microvasculature. It was mainly used for localizing the fluorescent microglia cells of different retinal layers. Several studies on the combined pv-OCT/SLO imaging system with fluorescent angiography, retinal neovascularization in retinopathy and tumor in vivo models has been reported recently [122].

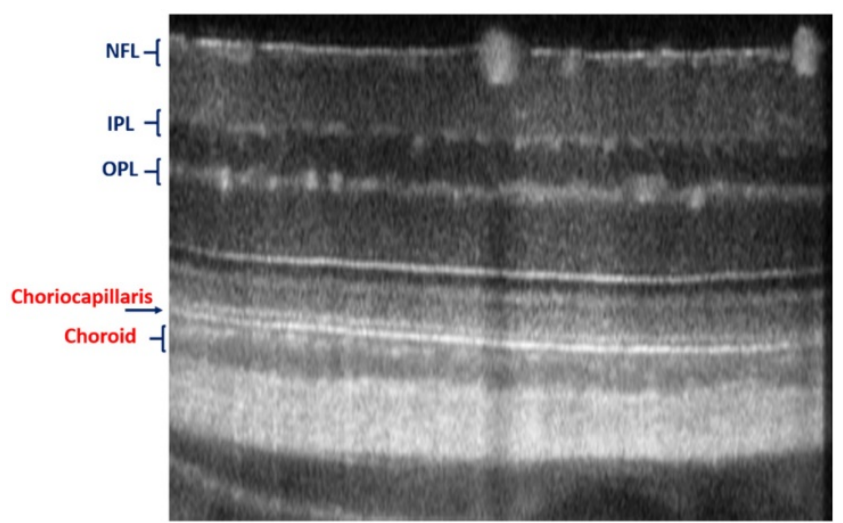

Figure 5. Imaging of choriocapillaris through OCT/SLO system.

The above study also have reported the fluorescence images and mapping of the retina in which the AO-SLO images are localized within the distinct axial focal planes and patterns of knocked
GFP expressed cells. The microglia-mediated inflammation has been reported in the number of disease etiologies indicated by its migration and morphological changes [123]. These morphological variations of the microglia from highly branched to amoeboid shape along the axis through the retinal layers can also be visualized by using the AO-SLO system. Apart from studying the microglia response to the injury, this gives significant in vivo proof for the role of microglia that provides insightful scientific evidences required for treatment of DR and other ocular complications.

\section{Nanotechnology in Ocular Drug Delivery}

Ocular drug delivery remains an formidable challenge to researchers despite several efforts $[124,125]$. The development of an effective ocular drug delivery system becomes an important objective for pharmaceutical engineers and scientists. Most of the frontal ocular diseases are treated through topical and sub-conjunctival administration of drugs in the form of solutions, ointment, and suspensions. Whereas, intravitreal injection of drugs is the predominant route of administration for the posterior ocular diseases. Administration of drugs into the intravitreal region are still facing poor ocular bioavailability owing to the pathophysiological and anatomical barriers in the eye. Recent studies urged the

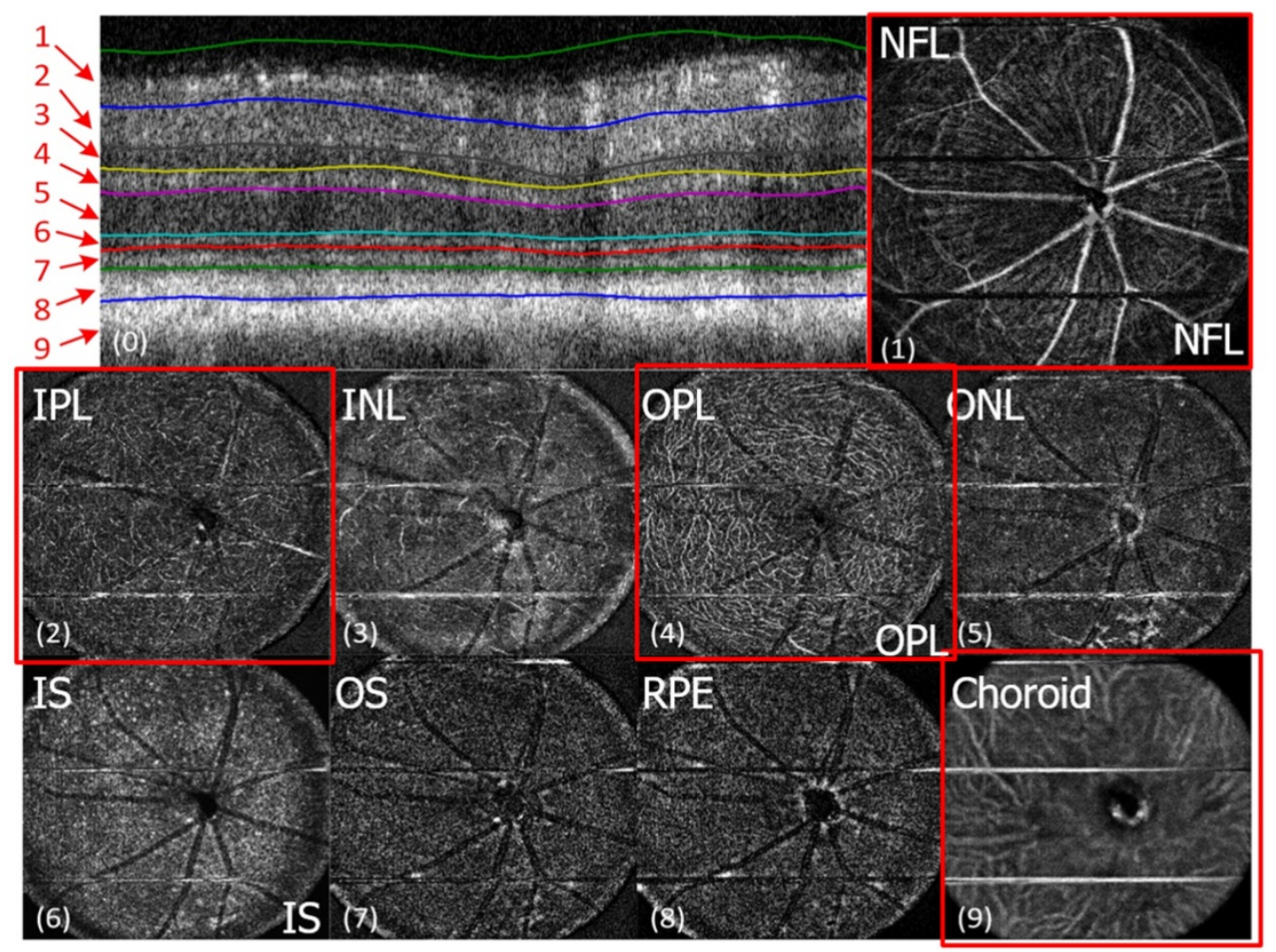

Figure 6. In vivo imaging of microvasculature layers and depth localization through pv-OCT/SLO system. Micrographs showing pv-OCT/SLO imaging showing images visualized at different layers such as nerve fiber layer (NFL), inner plexiform layer (IPL), inner nuclear layer (INL), outer plexiform layer (OPL), outer nuclear layer (ONL), inner segment (IS), outer segment (OS), retinal pigment epithelium (RPE), and choroid, respectively. (Adapted from Goswami et al. 2016 [163]). 
importance of nanotechnology-based drug delivery carriers such as nano-emulsions, nano-suspensions, dendrimers, liposomes, niosomes, cyclodextrin, etc. for the effective treatment and therapy for ocular complications [126-129]. The current promising drug delivery systems are nanomicelles, nanodevices, soft contact lens, bioadhesive systems, microfabricated systems, implants, cell encapsulation devices etc. [130-133]. Nanotechnology offers targeted drug delivery and sustained release of the therapeutic drug at the site [134]. The objective of such targeted delivery and controlled release is the effective management of pharmacokinetics, pharmacodynamics, immunogenicity, and non-specific toxicity.

\section{Nanomedicine}

Nanomedicine plays a significant role in diagnosis and novel approaches for therapeutic ocular drug delivery $[135,136]$. The use of nanotechnologybased drug delivery systems such as nanomicelles, solid lipid nanoparticles (nanospheres and nanocapsules), nano-suspensions, and drug loaded nanocarrier (Nanodrug) gives better solution to solubility and bioavailability of various poorly soluble therapeutic drugs especially in the posterior ocular diseases [137]. These drugs can also be targeted to allow the site-specific delivery and minimal side effects to the nearby cells [138]. Table 4 represented the suitable ocular nano drug delivery formulations like liquid, semi-solid or solid forms, route of drug administration, drug loading dosage and dosage intervals, release and retention time, drug concentration in vitreous for various retinal diseases. The particles, gels and implants are different drug formulations for intravitreal injections for posterior ocular diseases. Nanodized drug delivery systems distribute the drug at the target cells. The injected nanodrug carriers should be toxic free, with physiological $\mathrm{pH}$, should not induce aggregation in the vitreous fluids. Clinically used therapeutic compounds are simple lquid form (Ranibizumab or bevacizumab) or implants. The degradable (Ozurdex) and the non-degradable polymeric implants (Iluvein, Retisert) are eliminated from the anterior or posterior route. The presence of enzymes such as metalloproteinases, heparinase etc. could contribute in the polymeric degradation however sparse information is available on the elimination route of non-degradable implants [139-142]. Gels are used in drug delivery owing to their sustained drug release into the vitreous region. Thermoresponsive hydro/ nanogels like PLGA-PEG-PLGA are attractive with dual characteristics of aqueous form during injection and gel formation inside the vitreous [143]. Sustained drug release can be extended by incorporating into particles (polymeric miscelles) within gels [144,145]. Moreover, the utilization of hyluranic acid as gelling material is an effective method for drug delivery, but cationic particles should not be chosen as it forms aggregation in the vitreous humor [143].

Potential tissue barriers for ocular drug delivery are cornea, sclera and conjunctiva in frontal site. Whereas in the back of the eye are vitreous, inner limiting membrane (ILM), retinal pigment epithelium (RPE) and choroid. The frontal barriers consist of tight junctions in which small and large molecules upto $5 \mathrm{kDa}$ can permeate $[146,147]$. On the contrary, small nanoparticles, lipophilic compounds, drugs, proteins can diffuse easily into the posterior barriers [148-151]. Similarly, the vitreous-retinal barrier plays major role in nanoparticles drug delivery to retinal region. It depends upon various properties of carriers such as particle charge, surface structure, and hydrophobicity. Size of the injected particles affects the diffusion into retina and vitreous. The vitreous having pore size of $550 \mathrm{~nm}$ allows diffusion of large particles than ILM (having smaller mesh size of 10-100 $\mathrm{nm}$ in human). Drug delivery nanocarriers are essential for free drugs which is not able to reach its target site. Such nanocarriers are capable of diffuse and penetrate into both vitreous and ILM owing to their tunable properties. It is important that the design of nanostructures with anionic and neutral surface charge is used. Also, these surface charged nanoparticles of mean size 132-350 nm find it difficult for retinal penetration $[152,153]$. This could be due to non-uniform monodispersion of nanoparticles, i.e, only the smaller nanoparticles are able to penetrate into the retina. Few research works reported that most consistent retinal penetration is visible in soluble molecules such as PCL-PEG miscelles as ideal drug delivery carriers. These have effective intracellular properties; however the propertics may vary with different target retinal cell types [142,154]. The other polymeric nanomaterials also find enormous application in the treatment of DR and its several complications are poly (lactic acid) (PLA), chitosan, gelatin, poly (methyl methacrylate) (PMMA), poly (2-hydroxyethyl methacrylate) (pHEMA), and polyethyleneimine (PEI)-Chitosan.

The application of nanomaterials is emerging in ocular research especially in the treatment and therapies of DR. Nanoparticles such as silver, gold, titanium dioxide have their intrinsic therapeutic properties and potentials [155]. Early literature also shows that these metal based nanoparticles are being used in the treatment of DR [156-158]. Retinal neovascularization is the most critical factor in DR pathogenesis. The anti-angiogenic effects of silicate nanoparticles induced by VEGF on retinal 
neovascularization were tested [159]. It has been found that no toxic effects on retinal tissues on administration, and reduces retinal neovascularization. Hence, these nanoparticles are suitable for the treatment of VEGF induced neovascularization.

Fluoresecent based nanomaterials for non-invasive in vivo imaging plays major role in early diagnosis and treatment planning. Some of the fluorescent materials are Rhodamine, porphyrin, fluorescein isothiocyanate (FITC), green fluorescence protein (GFP), etc. Our former research groups have carried out imaging based diagnosis of tumor neovascularization in retinal layers through OCT using fluorescent nanoparticles. Porphyrin nanoparticles were used for the real time tracking of neovasculature in vivo. Figure 7 shows the representative OCT images of the tumor development in retina of mice showing the encapsulation of porphyrin with the newly formed tiny blood vessels of the retina (shown in dotted yellow box of Figure 7a). In the meanwhile, the normal retinal blood vessels are larger in size (shown in red box of Figure 7a) and Figure $7 d$-e represented the respective green filter images. The combined approach of non-invasive imaging based early diagnosis, nanotherapy is essential in the modern medical era.

Henceforth, the future perspectives of nanotechnology found to have multiple applications in ophthalmology. It helps in the development of nanodevices and nanocarriers for the treatment of various ocular complications in specific diabetic retinopathy (DR) and its associated complications. Furthermore, nanotechnology promotes the development of a 3D contact lens incorporated with nanomaterial encapsulated drugs for efficient drug delivery and treatment. 3D printing technology simplifies the development of therapeutic devices using either polymeric or metallic forms. Also, it will be helpful for medical engineers for the treatment and therapy using advanced tools [160]. This technology has enormous potential and possesses very high impact on the manufacturing of customized 3D printed ocular prototypes such as the retina, lens, cornea in the near future [161].

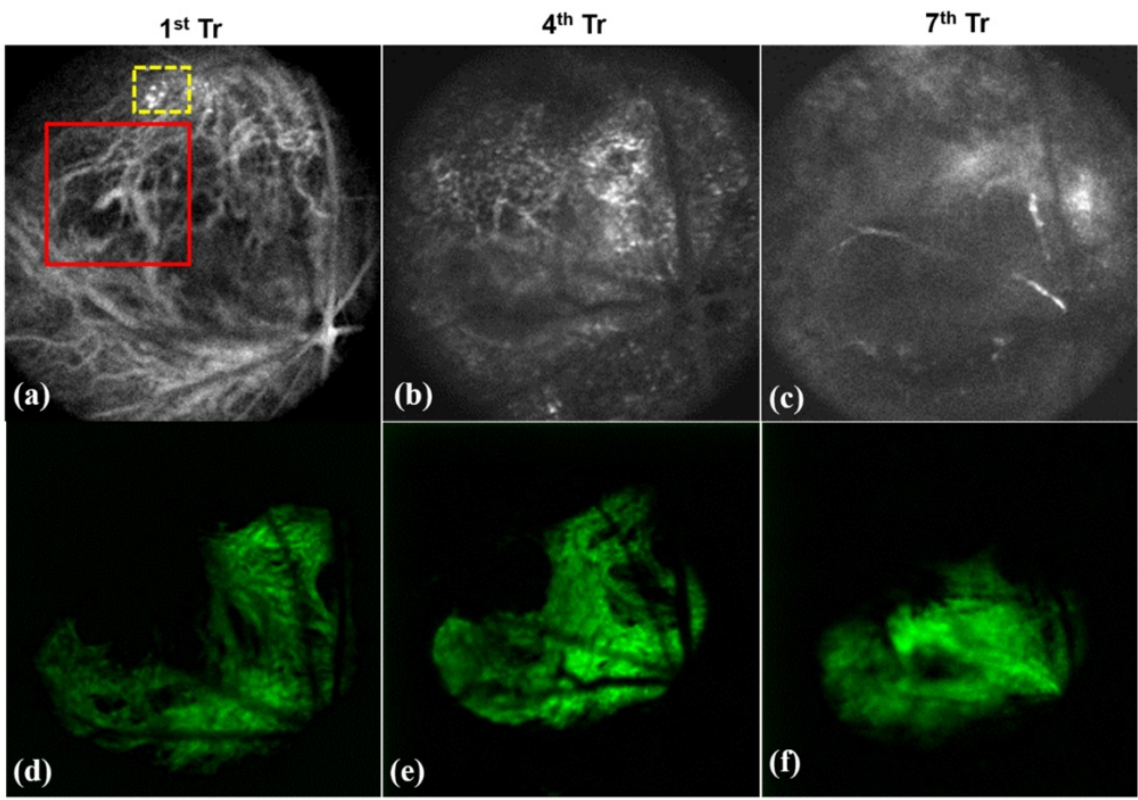

Figure 7. Visualization of porphyrin nanoparticles localized vasculature of in vivo mice showing (a-c) OCT images of the neovasculature (new tiny blood vessels) localized by porphyrin nanoparticles (as in yellow box) treated on 1 st, $4^{\text {th }}$ and $7^{\text {th }}$ day and (d-e) represented its respective green filter images. (Red box in Figure 7a showing the normal blood vessels which is larger than the newly formed vasculature).

Table 4. Intravitreal administration of various Nano drug delivery systems

\begin{tabular}{|c|c|c|c|c|c|c|c|}
\hline Material & Formulation & Drug compound & $\begin{array}{l}\text { Drug loading }(\mu \mathrm{g} / \mathrm{mg}) \\
\text { or total dose }(\mu \mathrm{g})\end{array}$ & $\begin{array}{l}\text { In vitro Release time } \\
\text { (days) or release rate } \\
\text { ( } \mu \mathrm{g} / \text { day) }\end{array}$ & $\begin{array}{l}\text { Time duration of } \\
\text { action (days) }\end{array}$ & $\begin{array}{l}\text { Concentration in } \\
\text { vitreous }(\mu \mathrm{M})\end{array}$ & Ref \\
\hline Chitosan coated PLGA & Solid & Methotrexate & $400 \mu \mathrm{g} / \mathrm{mg} ; 400 \mu \mathrm{g}$ & & 33 days & $0.1-1.0$ & [186] \\
\hline PVA-Silicone laminate & Implants & Fluocinolone acetonide & $590 \mu \mathrm{g}$ & $0.3-0.6 \mu \mathrm{g} / \mathrm{d}$ & $2.5-3$ years & $0.2-0.4$ & [187] \\
\hline PVA, ethylene vinyl acetate & & Ganciclovir & $4.5 \mathrm{mg}$ & $1.4 \mu \mathrm{g} / \mathrm{h}$ & 150 - 240 days & $7.5-29$ & [188] \\
\hline Silicone, poly vinyl acetate & & Fluocinolone acetonide & $190 \mu \mathrm{g}$ & $0.2 \mu \mathrm{g} /$ day & 728 days & $0.1-2$ & [189] \\
\hline PLGA & & Dexamethasone & $700 \mu \mathrm{g}$ & $1 \mu \mathrm{g} / \mathrm{h}$ & 90 days & 0.6 & {$[190,191]$} \\
\hline PLGA-PEG-PLGA gel & Semi-solid & Dexamethasone & $1 \mathrm{mg} / \mathrm{mL}$ & $>10$ days & $>9$ & $3-23$ & [192] \\
\hline PLGA nano/microparticles & Liquid form & $\begin{array}{l}\text { Dexamethasone } \\
\text { Bevacizumab }\end{array}$ & $\begin{array}{l}40 \mu \mathrm{g} / \mathrm{mg} ; 200 \mu \mathrm{g} \\
12.5 \mathrm{mg} / \mathrm{mL} \text { of } \\
\text { suspension; } 62.5 \mu \mathrm{g}\end{array}$ & & $\begin{array}{l}>20 \\
>30\end{array}$ & $\begin{array}{l}21-31 \\
63\end{array}$ & $\begin{array}{l}{[193]} \\
{[194]}\end{array}$ \\
\hline
\end{tabular}




\section{Conclusion and future directions}

Diabetic retinopathy (DR) is one of the vital ocular complications generally occurred among the middle-aged people worldwide. The current treatment methods of DR involve intraocular or intravitreal chemotherapeutic injections, laser therapy, which leads to several post-treatment risks. Subsequently, stem cell therapies are though effective, but a pre-emptive nano-theranostic tool has yet to be developed. Presently our group is working on the research project on the development of a combination of non-invasive early diagnostic imaging system with nano-drug delivery approaches which are quintessential for effective ocular repair. This strategy could be an appropriate alternative to conventional treatment. Herein, this review work comprehensively discussed the diabetic retinopathy, its mechanism, biomedical imaging modalities, drugs (both natural and chemical), present and future perspectives of DR treatment and nanomaterials based ocular drug delivery approaches. Apart from the review of the current approaches, this work necessitates the essentiality of innovative non-invasive nano-theranostic imaging system and nano-drug delivery approaches for DR to achieve effective outcomes in patients. We also recommended the utilization and importance of 3D printing technology in the ocular research. This leads to the development of non-invasive nano-therapeutic and biomedical implants essential for the future clinical diagnosis and treatment of various ocular complications.

\section{Abbreviations}

DR: diabetic retinopathy; BRB: blood retinal barrier; OCT: optical coherence tomography; NPDR: non-proliferative diabetic retinopathy; PDR: proliferative diabetic retinopathy; DME: diabetic macular edema; ICAM-1: intercellular adhesion molecule-I; VEGF: vascular endothelial growth factor (VEGF); NOS: nitrous oxide synthase; HBP: hexosamine biosynthesis pathway; AGE: advanced glycation end products; PKC: protein kinase C; RhoA: rhodamine A; ROCK1: rho-associated coiled-coilcontaining protein kinase 1; GTPase: guanine triphosphate hydrolase; IGF: insulin like growth factor; RAAS: renin-angiotensin-aldosterone system; ER: endoplasmic reticulum; RPE: retinal pigment epithelium; DNA: deoxyribonucleic acid; RNA: ribonucleic acid; TGF- $\beta$ : transforming growth factor- $\beta$; BMP2: bone morphogenic protein 2; TLR2: Toll-like receptor 2; HG: high glucose; TXNIP: Thioredoxin interacting proteins; NAD: nicotinamide adenine dinucleotide; $\mathrm{NADH}^{+}$: nicotinamide adenine dinucleotide dehydrogenase; $\mathrm{NADPH}^{+}$: nicotinamide adenine dinucleotide phosphate dehydrogenase; DAG: diacylglycerol; ROS: reactive oxygen species; PRP: panretinal photocoagulation; ILM: inner limiting membrane; IPL: inner plexiform layer; and NFL: nerve fiber layer; IVTA: intravitreal administration of triamcinolone acetate; AMD: age-related macular degeneration; $\mathrm{VH}$ : vitreous hemorrhage; TRD: tractional retinal detachment; LP: laser photocoagulation; DRCR: Diabetic Retinopathy Clinical Research Network; ALR2: aldose reductase; FIELD: Fenofibrate Intervention and Event lowering in Diabetes; ETDRS: early treatment diabetic retinopathy study; PPAR-ү: peroxisome proliferator-activated receptor; MRSI: magnetic resonance spectroscopy imaging; PET: positron emission tomography; AO: adaptive optics; SLO: scanning laser ophthalmoscopy; OCTA: optical coherence tomography angiography; GFP: green fluorescence protein; CMOS: complementary metal oxide semiconductor; PLGA: poly(lactic-co-glycolic acid); PEG: poly(ethylene glycol); PLA: poly(lactic acid); PMMA: poly(methyl methacrylate); pHEMA: poly (2-hydroxyethyl methacrylate); PEI: polyethyleneimine; FITC: fluorescein isothiocyanate.

\section{Acknowledgements}

We sincerely acknowledge Dr. Pengfei Zhang, Eyepod, University of California, Davis, U.S.A for giving permission for using the figures in this review work. Also, we are thankful to Dr. Rajiv Ranjan related to the technical discussion of the project. Dr. Rajkumar is thankful to DST-SERB for the financial support and also sincere thanks to the Department of Physics and Centre of Nanotechnology of Indian Institute of Technology Roorkee.

\section{Funding Information}

This work is financially supported by the Department of Science and Technology-Science and Engineering Research Board (DST-SERB) under IMPRINT-II scheme, Project grant code: IMP/2018/ 001045, Government of India.

\section{Competing Interests}

The authors have declared that no competing interest exists.

\section{References}

1. Yau JWY, Rogers SL, Kawasaki R, et al. Global prevalence and major risk factors of diabetic retinopathy. Diabetes Care. 2012; 35: 556-64.

2. Leasher JL, Bourne RRA, Flaxman SR, et al. Global estimates on the number of people blind or visually impaired by diabetic retinopathy: a meta-analysis from 1990 to 2010. Diabetes Care. 2016; 39: 1643-9.

3. Brownrigg JRW, Hughes CO, Burleigh D, et al. Microvascular disease and risk of cardiovascular events among individuals with type 2 diabetes: a population-level cohort study. Lancet Diabetes Endocrinol. 2016; 4: 588-97.

4. Kawasaki R, Tanaka S, Tanaka S, et al. Risk of cardiovascular diseases is increased even with mild diabetic retinopathy: the Japan Diabetes Complications Study. Ophthalmology. 2013; 120: 574-82. 
5. Klein R, Zinman B, Gardiner R, et al. The Relationship of Diabetic Retinopathy to Preclinical Diabetic Glomerulopathy Lesions in Type 1 Diabetic. Diabetes. 2005; 54: 527-33.

6. Takagi M, Babazono T, Uchigata Y. Differences in risk factors for the onset of albuminuria and decrease in glomerular filtration rate in people with type 2 diabetes mellitus: implications for the pathogenesis of diabetic kidney disease. Diabet Med. 2015; 32: 1354-60.

7. Friedenwald J, Day R. The vascular lesions of diabetic retinopathy. Bull Johns Hopkins Hosp. 1950; 86: 253-4.

8. Group ETDRSR. Fundus photographic risk factors for progression of diabetic retinopathy: ETDRS report number 12. Ophthalmology. 1991; 98: 823-33.

9. Sohn EH, van Dijk HW, Jiao C, et al. Retinal neurodegeneration may precede microvascular changes characteristic of diabetic retinopathy in diabetes mellitus. Proc Natl Acad Sci. 2016; 113: E2655-64.

10. Solomon SD, Chew E, Duh EJ, et al. Diabetic retinopathy: a position statement by the American Diabetes Association. Diabetes Care. 2017; 40: 412-8.

11. Hawkins BT, Davis TP. The blood-brain barrier/neurovascular unit in health and disease. Pharmacol Rev. 2005; 57: 173-85.

12. Gardner TW, Davila JR. The neurovascular unit and the pathophysiologic basis of diabetic retinopathy. Graefe's Arch Clin Exp Ophthalmol. 2017; 255: $1-6$.

13. Xie K, Liu CY, Hasso AN, Crow RW. Visual field changes as an early indicator of glioblastoma multiforme progression: Two cases of functional vision changes before MRI detection. Clin Ophthalmol. 2015; 9: 1041-7.

14. Wilkinson CP, Ferris FL, Klein RE, et al. Proposed international clinical diabetic retinopathy and diabetic macular edema disease severity scales. Ophthalmology. 2003; 110: 1677-82.

15. Emptage NP, Kealey S, Lum FC, Garratt S. Preferred Practice Pattern: Diabetic retinopathy. Am J Ophthalmol [Internet]. 2014; Updated Ja: http://www.aao. org/preferred-practice-pattern/diab. Available at: http://dx.doi.org/10. 1016/S0140-6736(09)62124-3.

16. Lai CM, Dunlop SA, May LA, et al. Generation of transgenic mice with mild and severe retinal neovascularisation. Br J Ophthalmol. 2005; 89: 911-6.

17. Kovach JL, Isildak H, Sarraf D. Crystalline retinopathy: Unifying pathogenic pathways of disease. Surv Ophthalmol [Internet]. 2019; 64: 1-29. Available at: https://doi.org/10.1016/j.survophthal.2018.08.001.

18. Rosenberg AE, Kattapuram S V, Nielsen GP. 14 - Infection of Bone A2 Kradin, Richard L. Diagnostic Pathol Infect Dis (Second Ed [Internet]. 2018; 114: 369-403. Available at: https://www.sciencedirect.com/science/article/ pii/B978032344585600014X.

19. Kisilevsky E, Freund P, Margolin E. Mitochondrial disorders and the eye. Surv Ophthalmol [Internet]. 2020; 65: 294-311. Available at: https://doi.org/10. 1016/j.survophthal.2019.11.001.

20. Ohkubo Y, Kishikawa H, Araki E, et al. Intensive insulin therapy prevents the progression of diabetic microvascular complications in Japanese patients with non-insulin-dependent diabetes mellitus: a randomized prospective 6-year study. Diabetes Res Clin Pract. 1995; 28: 103-17.

21. Group DC and CTR. The effect of intensive treatment of diabetes on the development and progression of long-term complications in insulindependent diabetes mellitus. N Engl J Med. 1993; 329: 977-86.

22. Group UKPDS (UKPDS). Intensive blood-glucose control with sulphonylureas or insulin compared with conventional treatment and risk of complications in patients with type 2 diabetes (UKPDS 33). Lancet. 1998; 352: 837-53.

23. Cernea S, Dobreanu M. Diabetes and beta cell function: From mechanisms to evaluation and clinical implications. Biochem Medica. 2013; 23: 266-80.

24. Das A, McGuire PG, Rangasamy S. Diabetic Macular Edema: Pathophysiology and Novel Therapeutic Targets. Ophthalmology [Internet]. 2015 [cited 6 September 2019]; 122: 1375-94. Available at: https://www.sciencedirect.com/ science/article/pii/S016164201500305X?via\%3Dihub.

25. Hammes HP, Feng Y, Pfister F, Brownlee M. Diabetic retinopathy: Targeting vasoregression. Diabetes. 2011; 60: 9-16.

26. JOUSSEN AM, POULAKI V, LE ML, et al. A central role for inflammation in the pathogenesis of diabetic retinopathy. FASEB J [Internet]. 2004 [cited 6 September 2019]; 18: 1450-2. Available at: http://www.fasebj.org/doi/10. 1096/fj.03-1476fje.

27. Semeraro F, Cancarini A, Dell'Omo R, Rezzola S, Romano MR, Costagliola C. Diabetic retinopathy: Vascular and inflammatory disease. J Diabetes Res. 2015; 2015.

28. Donnelly R, Horton E. Pathophysiology of Diabetic. Vasc Complicat Diabetes. 2005; 9: 1-6.

29. Antonetti DA, Barber AJ, Khin S, Lieth E, Tarbell JM, Gardner TW. Vascular permeability in experimental diabetes is associated with reduced endothelial occludin content: vascular endothelial growth factor decreases occludin in retinal endothelial cells. Penn State Retina Research Group. Diabetes [Internet]. 1998 [cited 6 September 2019]; 47: 1953-9. Available at: http://www.ncbi.nlm.nih.gov/pubmed/9836530.

30. Leal EC, Manivannan A, Hosoya K-I, et al. Inducible Nitric Oxide Synthase Isoform Is a Key Mediator of Leukostasis and Blood-Retinal Barrier Breakdown in Diabetic Retinopathy. Investig Opthalmology Vis Sci [Internet]. 2007 [cited 6 September 2019]; 48: 5257. Available at: http://iovs.arvojournals. org/article.aspx?doi=10.1167/iovs.07-0112.

31. Vorum H, Ditzel J. Disturbance of inorganic phosphate metabolism in diabetes mellitus: Its relevance to the pathogenesis of diabetic retinopathy. J Ophthalmol. 2014; 2014.
32. Das A, Stroud S, Mehta A, Rangasamy S. New treatments for diabetic retinopathy. Diabetes, Obes Metab. 2015; 17: 219-30.

33. El-Asrar AMA, Dralands L, Missotten L, Al-Jadaan IA, Geboes K. Expression of Apoptosis Markers in the Retinas of Human Subjects with Diabetes. Investig Opthalmology Vis Sci [Internet]. 2004 [cited 6 September 2019]; 45: 2760. Available at: http://iovs.arvojournals.org/article.aspx?doi=10.1167/ iovs.03-1392.

34. Barber AJ, Lieth E, Khin SA, Antonetti DA, Buchanan AG, Gardner TW. Neural apoptosis in the retina during experimental and human diabetes: Early onset and effect of insulin. J Clin Invest. 1998; 102: 783-91.

35. Oshitari T, Hata N, Yamamoto S. Endoplasmic reticulum stress and diabetic retinopathy. Vasc Health Risk Manag [Internet]. 2008 [cited 7 September 2019]; 4: 115-22. Available at: http://www.ncbi.nlm.nih.gov/pubmed/18629365.

36. Kwa FAA, Thrimawithana TR. Epigenetic modifications as potential therapeutic targets in age-related macular degeneration and diabetic retinopathy. Drug Discov Today [Internet]. 2014; 19: 1387-93. Available at: http://dx.doi.org/10.1016/j.drudis.2014.03.026.

37. Reddy MA, Zhang E, Natarajan R. Epigenetic mechanisms in diabetic complications and metabolic memory. Diabetologia [Internet]. 2015 [cited 7 September 2019]; 58: 443-55. Available at: http://www.ncbi.nlm.nih.gov/ pubmed $/ 25481708$.

38. Perrone L, Matrone C, Singh LP. Epigenetic Modifications and Potential New Treatment Targets in Diabetic Retinopathy. J Ophthalmol [Internet]. 2014 [cited 7 September 2019]; 2014: 1-10. Available at: http://www.ncbi.nlm.nih. gov/pubmed/25165577

39. Cai X, McGinnis JF. Diabetic retinopathy: animal models, therapies, and perspectives. J Diabetes Res. 2016; 2016.

40. Sugiyama T. Role of P2X7 receptors in the development of diabetic retinopathy. World J Diabetes. 2014; 5: 141

41. Singh LP. Thioredoxin interacting protein (TXNIP) and pathogenesis of diabetic retinopathy. J Clin Exp Ophthalmol. 2013; 4.

42. Stehouwer CDA, Lambert J, Donker AJM, van Hinsbergh VWM. Endothelial dysfunction and pathogenesis of diabetic angiopathy. Cardiovasc Res. 1997; 34: 55-68.

43. Brownlee M. Biochemistry and molecular cell biology of diabetic complications. Nature. 2001; 414: 813.

44. Jo DH, Cho CS, Kim JH, Jun HO, Kim JH. Animal models of diabetic retinopathy: Doors to investigate pathogenesis and potential therapeutics. J Biomed Sci [Internet]. 2013; 20: 1. Available at: Journal of Biomedical Science.

45. White N. Prolonged effect of intensive therapy on the risk of retinopathy complication in patients with type 1 diabetes mellitus. Arch Ophthalmol. 2009; 126: 1707-15.

46. Jo DH, Cho CS, Kim JH, Jun HO, Kim JH. Animal models of diabetic retinopathy: doors to investigate pathogenesis and potential therapeutics. J Biomed Sci. 2013; 20: 38.

47. Net D. 3 year follow up randomized trial comparing focal/grid and IVTA for DMO. Arch Ophthalmol. 2009; 127: 245-51.

48. Jo DH, Kim JH, Kim JH. How to overcome retinal neuropathy: The fight against angiogenesisrelated blindness. Arch Pharm Res. 2010; 33: 1557-65.

49. Do D V., Nguyen QD, Boyer D, et al. One-year outcomes of the da VINCI study of VEGF trap-eye in eyes with diabetic macular edema. In: Ophthalmology. 2012

50. Rajendram R, Fraser-Bell S, Kaines A, et al. A 2-year prospective randomized controlled trial of intravitreal bevacizumab or laser therapy (BOLT) in the management of diabetic macular edema: 24-Month data: Report 3. Arch Ophthalmol. 2012; 130: 972-9.

51. Nguyen QD, Brown DM, Marcus DM, et al. Ranibizumab for diabetic macular edema: Results from 2 phase iii randomized trials: RISE and RIDE. Ophthalmology. 2012; 119: 789-801.

52. Heo JW, Kim JH, Cho CS, et al. Inhibitory activity of bevacizumab to differentiation of retinoblastoma cells. PLoS One. 2012; 7: 1-7.

53. Kurihara T, Westenskow PD, Bravo S, Aguilar E, Friedlander M. Targeted deletion of Vegfa in adult mice induces vision loss. J Clin Invest. 2012; 122: 4213-7.

54. Fischer MD, Huber G, Beck SC, et al. Noninvasive, in vivo assessment of mouse retinal structure using optical coherence tomography. PLoS One. 2009; 4

55. Kim JH, Kim JH, Jun HO, Yu YS, Kim KW. Inhibition of protein kinase C $\delta$ attenuates blood-retinal barrier breakdown in diabetic retinopathy. Am J Pathol [Internet]. 2010; 176: 1517-24. Available at: http://dx.doi.org/10. 2353/ajpath.2010.090398

56. Lim Y, Jo DH, Kim JH, et al. Human apolipoprotein(a) kringle V inhibits ischemia-induced retinal neovascularization via suppression of fibronectinmediated angiogenesis. Diabetes. 2012; 61: 1599-608.

57. Ahn J, Woo SJ, Chung H, Park KH. The Effect of Adjunctive Intravitreal Bevacizumab for Preventing Postvitrectomy Hemorrhage in Proliferative Diabetic Retinopathy. Ophthalmology [Internet]. 2011 [cited 6 September 2019]; 118: 2218-26. Available at: https://www.sciencedirect.com/science/ article/pii/S0161642011003289?via\%3Dihub.

58. Brănisteanu DC onstanti., Bilha A, Moraru A. Vitrectomy surgery of diabetic retinopathy complications. Rom J Ophthalmol. 2016; 60: 31-6.

59. Group ETDRSR. Photocoagulation for diabetic macular edema: Early Treatment Diabetic Retinopathy Study report no. 4. Int Ophthalmol Clin. 1987; 27: 265-72.

60. Raskin P, Arauz-Pacheco C. The treatment of diabetic retinopathy: a view for the internist. Ann Intern Med. 1992; 117: 226-33. 
61. Group ETDRSR. Treatment techniques and clinical guidelines for photocoagulation of diabetic macular edema: Early Treatment Diabetic Retinopathy Study report number 2. Ophthalmology. 1987; 94: 761-74.

62. Ferris FL. How effective are treatments for diabetic retinopathy? Jama. 1993; 269: 1290-1.

63. Group DRS. Preliminary report on effects of photocoagulation therapy. The Diabetic Retinopathy Study Research Group. Am J Ophthalmol. 1976; 81: 383-96.

64. Elman MJ, Aiello LP, Beck RW, et al. Randomized trial evaluating ranibizumab plus prompt or deferred laser or triamcinolone plus prompt laser for diabetic macular edema. Ophthalmology. 2010; 117: 1064-77.

65. Heier JS, Korobelnik J-F, Brown DM, et al. Intravitreal aflibercept for diabetic macular edema: 148-week results from the VISTA and VIVID studies. Ophthalmology. 2016; 123: 2376-85.

66. Brown DM, Nguyen QD, Marcus DM, et al. Long-term outcomes of ranibizumab therapy for diabetic macular edema: the 36-month results from two phase III trials: RISE and RIDE. Ophthalmology. 2013; 120.

67. Wells JA, Glassman AR, Ayala AR, et al. Aflibercept, bevacizumab, or ranibizumab for diabetic macular edema: two-year results from a comparative effectiveness randomized clinical trial. Ophthalmology. 2016; 123: 1351-9.

68. Network DRCR. Aflibercept, Bevacizumab, or Ranibizumab for Diabetic Macular Edema Two-Year Results from a Comparative Effectiveness Randomized Clinical Trial. Ophthalmology. 2016; 123: 1351-9.

69. Avery RL, Pearlman J, Pieramici DJ, et al. Intravitreal bevacizumab (Avastin) in the treatment of proliferative diabetic retinopathy. Ophthalmology. 2006; 113: $1695-705$

70. Gross JG, Glassman AR, Jampol LM, et al. Panretinal photocoagulation vs intravitreous ranibizumab for proliferative diabetic retinopathy: a randomized clinical trial. Jama. 2015; 314: 2137-46.

71. Talks J, Daien V, Finger RP, et al. The use of real-world evidence for evaluating anti-vascular endothelial growth factor treatment of neovascular age-related macular degeneration. Surv Ophthalmol. 2019; 64: 707-19.

72. Schatz H, Madeira D, McDonald HR, Johnson RN. Progressive enlargement of laser scars following grid laser photocoagulation for diffuse diabetic macular edema. Arch Ophthalmol. 1991; 109: 1549-51.

73. Mccannel CA. Meta-analysis of endophthalmitis after intravitreal injection of anti-vascular endothelial growth factor agents: causative organisms and possible prevention strategies. Retina. 2011; 31: 654-61.

74. Tolentino M. Systemic and ocular safety of intravitreal anti-VEGF therapies for ocular neovascular disease. Surv Ophthalmol. 2011; 56: 95-113.

75. Bakri SJ, Pulido JS, McCannel CA, Hodge DO, Diehl N, Hillemeier J. Immediate intraocular pressure changes following intravitreal injections of triamcinolone, pegaptanib, and bevacizumab. Eye. 2009; 23: 181.

76. Sarao V, Veritti D, Boscia F, Lanzetta P. Intravitreal steroids for the treatment of retinal diseases. Sci World J. 2014; 2014

77. Osaadon P, Fagan XJ, Lifshitz T, Levy J. A review of anti-VEGF agents for proliferative diabetic retinopathy. Eye [Internet]. 2014; 28: 510-20. Available at: http://dx.doi.org/10.1038/eye.2014.13.

78. Ciulla TA, Amador AG, Zinman B. Diabetic retinopathy and diabetic macular edema: pathophysiology, screening, and novel therapies. Diabetes Care. 2003; 26: 2653-64.

79. Gupta SK, Kumar B, Nag TC, et al. Curcumin prevents experimental diabetic retinopathy in rats through its hypoglycemic, antioxidant, and antiinflammatory mechanisms. J Ocul Pharmacol Ther. 2011; 27: 123-30.

80. Chen XR, Besson VC, Palmier B, Garcia Y, Plotkine M, Marchand-Leroux C. Neurological recovery-promoting, anti-inflammatory, and anti-oxidative effects afforded by fenofibrate, a PPAR alpha agonist, in traumatic brain injury. J Neurotrauma. 2007; 24: 1119-31.

81. Campochiaro PA. Reduction of diabetic macular edema by oral administration of the kinase inhibitor PKC412. Invest Ophthalmol Vis Sci. 2004; 45: 922-31.

82. Sheetz MJ, Aiello LP, Davis MD, et al. The effect of the oral PKC $\beta$ inhibitor ruboxistaurin on vision loss in two phase 3 studies. Invest Ophthalmol Vis Sci. 2013; 54: 1750-7.

83. Davis MD, Sheetz MJ, Aiello LP, et al. Effect of ruboxistaurin on the visual acuity decline associated with long-standing diabetic macular edema. Invest Ophthalmol Vis Sci. 2009; 50: 1-4.

84. Ludwig PE, Freeman SC, Janot AC. Novel stem cell and gene therapy in diabetic retinopathy, age related macular degeneration, and retinitis pigmentosa. Int J Retin Vitr. 2019; 5: 7.

85. Rodríguez ML, Pérez S, Mena-Mollá S, Desco MC, Ortega ÁL. Oxidative Stress and Microvascular Alterations in Diabetic Retinopathy: Future Therapies. Oxid Med Cell Longev. 2019; 2019.

86. Ting KK, Zhao $\mathrm{Y}$, Shen $\mathrm{W}$, et al. Therapeutic regulation of VE-cadherin with a novel oligonucleotide drug for diabetic eye complications using retinopathy mouse models. Diabetologia. 2019; 62: 322-34.

87. Ofori SN, Unachukwu CN. Holistic approach to prevention and management of type 2 diabetes mellitus in a family setting. Diabetes, Metab Syndr Obes targets Ther. 2014; 7: 159 .

88. Williams DR. Imaging single cells in the living retina. Vision Res. 2011; 51: 1379-96

89. Ramos de Carvalho JE, Verbraak FD, Aalders MC, van Noorden CJ, Schlingemann RO. Recent advances in ophthalmic molecular imaging. Surv Ophthalmol [Internet]. 2014; 59: 393-413. Available at: http://dx.doi.org/10. 1016/j.survophthal.2013.09.005
90. van Leeuwen FWB, Hardwick JCH, van Erkel AR Luminescence-based imaging approaches in the field of interventional molecular imaging. Radiology. 2015; 276: 12-29.

91. Gutowski MB, Wilson L, Van Gelder RN, Pepple KL. In vivo bioluminescence imaging for longitudinal monitoring of inflammation in animal models of uveitis. Invest Ophthalmol Vis Sci. 2017; 58: 1521-8.

92. Miyamoto J, Tatsuzawa K, Owada K, Kawabe T, Sasajima H, Mineura K. Usefulness and limitations of fluorine-18-fluorodeoxyglucose positron emission tomography for the detection of malignancy of orbital tumors. Neurol Med Chir (Tokyo). 2008; 48: 495-9.

93. García-Rojas L, Adame-Ocampo G, Mendoza-Vázquez G, Alexánderson E, Tovilla-Canales JL. Orbital positron emission tomography/computed tomography (PET/CT) imaging findings in graves ophthalmopathy. BMC Res Notes. 2013; 6: 353

94. Salmon E, Ir CB, Hustinx R. Pitfalls and limitations of PET/CT in brain imaging. In: Seminars in nuclear medicine. Elsevier; 2015.

95. Muzaffar R, Shousha MA, Sarajlic L, Osman MM. Ophthalmologic abnormalities on FDG-PET/CT: a pictorial essay. Cancer Imaging. 2013; 13: 100

96. Mo S, Krawitz B, Efstathiadis E, et al. Imaging foveal microvasculature: optical coherence tomography angiography versus adaptive optics scanning light ophthalmoscope fluorescein angiography. Invest Ophthalmol Vis Sci. 2016; 57: OCT130-40

97. Lee J, Rosen R. Optical coherence tomography angiography in diabetes. Curr Diab Rep. 2016; 16: 123

98. Alt C, Biss DP, Tajouri N, Jakobs TC, Lin CP. An adaptive-optics scanning laser ophthalmoscope for imaging murine retinal microstructure. In: Ophthalmic Technologies XX. International Society for Optics and Photonics; 2010.

99. Jian Y, Zawadzki RJ, Sarunic M V. Adaptive optics optical coherence tomography for in vivo mouse retinal imaging. J Biomed Opt. 2013; 18: 56007.

100. Sharma R, Yin L, Geng Y, et al. In vivo two-photon imaging of the mouse retina. Biomed Opt Express. 2013; 4: 1285-93.

101. Geng Y, Dubra A, Yin L, et al. Adaptive optics retinal imaging in the living mouse eye. Biomed Opt Express. 2012; 3: 715-34.

102. Hong XJJ, Sandeep CSS, Shinoj VK, et al. Noninvasive and Noncontact Sequential Imaging of the Iridocorneal Angle and the Cornea of the Eye. Transl Vis Sci Technol. 2020; 9: 1.

103. Andrews JPM, Portal C, Walton T, et al. Non-invasive in vivo imaging of acute thrombosis: development of a novel factor XIIIa radiotracer. Eur Hear J Cardiovasc Imaging. 2019; 44: 1-10.

104. Hadoux X, Hui F, Lim JKH, et al. Non-invasive in vivo hyperspectral imaging of the retina for potential biomarker use in Alzheimer's disease. Nat Commun. 2019; 10: 1-12.

105. Mazzoni F, Müller C, DeAssis J, Lew D, Leevy WM, Finnemann SC. Non-invasive in vivo fluorescence imaging of apoptotic retinal photoreceptors. Sci Rep. 2019; 9: 1-9.

106. Ko YJ, Lee JW, Yang EJ, et al. Non-invasive in vivo imaging of caspase-1 activation enables rapid and spatiotemporal detection of acute and chronic inflammatory disorders. Biomaterials [Internet]. 2020; 226: 119543. Available at: https://doi.org/10.1016/j.biomaterials.2019.119543.

107. Julius A, Hopper W. A non-invasive, multi-target approach to treat diabetic retinopathy. Biomed Pharmacother [Internet]. 2019; 109: 708-15. Available at: https://doi.org/10.1016/j.biopha.2018.10.185.

108. Grzybowski A, Kanclerz P. Early detection of diabetic retinopathy with flicker electroretinography, proteomics, and oximetry. Surv Ophthalmol [Internet]. 2019; 64: 132-3. Available at: https://doi.org/10.1016/j.survophthal.2018.07. 002.

109. Mansour RF. Evolutionary Computing Enriched Computer-Aided Diagnosis System for Diabetic Retinopathy: A Survey. IEEE Rev Biomed Eng. 2017; 10: $334-49$.

110. Santos T, Ribeiro L, Lobo C, Bernardes R, Serranho P. Validation of the automatic identification of eyes with diabetic retinopathy by OCT. 2012 IEEE 2nd Port Meet Bioeng ENBENG 2012. 2012.

111. Singh SR, Lupidi M, Mishra SB, Paez-Escamilla M, Querques G, Chhablani J. Unique optical coherence tomographic features in age-related macular degeneration. Surv Ophthalmol [Internet]. 2020; 65: 451-7. Available at: https://doi.org/10.1016/j.survophthal.2020.01.001.

112. Huang D, Swanson EA, Lin CP, et al. Optical coherence tomography. Science (80-). 1991; 254: 1178-81.

113. Sharp PF, Manivannan A, Xu H, Forrester JV. The scanning laser ophthalmoscope - a review of its role in bioscience and medicine. Phys Med Biol. 2004; 49: 1085

114. Drexler W, Fujimoto JG. State-of-the-art retinal optical coherence tomography. Prog Retin Eye Res. 2008; 27: 45-88.

115. Sun Z, Yang D, Tang Z, Ng DS, Cheung CY. Optical coherence tomography angiography in diabetic retinopathy: an updated review. Eye [Internet]. 2020; Available at: http://dx.doi.org/10.1038/s41433-020-01233-y.

116. de Carlo TE, Romano A, Waheed NK, Duker JS. A review of optical coherence tomography angiography (OCTA). Int J Retin Vitr. 2015; 1: 1-15.

117. Zawadzki RJ, Zhang P, Zam A, et al. Adaptive-optics SLO imaging combined with widefield OCT and SLO enables precise 3D localization of fluorescent cells in the mouse retina. Biomed Opt Express. 2015; 6: 2191-210.

118. Zhang P, Zam A, Jian Y, et al. In vivo wide-field multispectral scanning laser ophthalmoscopy-optical coherence tomography mouse retinal imager: 
longitudinal imaging of ganglion cells, microglia, and Müller glia, and mapping of the mouse retinal and choroidal vasculature. J Biomed Opt. 2015; 20: 126005 .

119. Giepmans BNG, Adams SR, Ellisman MH, Tsien RY. The fluorescent toolbox for assessing protein location and function. Science (80- ). 2006; 312: 217-24.

120. Zam A, Zhang P, Levine E, Pugh Jr EN, Burns M, Zawadzki RJ. Evaluation of OCT for quantitative in-vivo measurements of changes in neural tissue scattering in longitudinal studies of retinal degeneration in mice. In: Optical Coherence Tomography and Coherence Domain Optical Methods in Biomedicine XVIII. International Society for Optics and Photonics; 2014.

121. Zhang P, Zam A, Pugh Jr EN, Zawadzki RJ. Evaluation of state-of-the-art imaging systems for in vivo monitoring of retinal structure in mice: current capabilities and limitations. In: Ophthalmic Technologies Xxiv. International Society for Optics and Photonics; 2014.

122. Moisseiev E, Anderson JD, Oltjen S, et al. Protective Effect of Intravitreal Administration of Exosomes Derived from Mesenchymal Stem Cells on Retinal Ischemia. Curr Eye Res [Internet]. 2017; 42: 1358-67. Available at: https://doi.org/10.1080/02713683.2017.1319491.

123. Alt C, Runnels JM, Mortensen LJ, Zaher W, Lin CP. In vivo imaging of microglia turnover in the mouse retina after ionizing radiation and dexamethasone treatment. Invest Ophthalmol Vis Sci. 2014; 55: 5314-9.

124. Souto EB, Dias-Ferreira J, López-Machado A, et al. Advanced formulation approaches for ocular drug delivery: State-of-the-art and recent patents. Pharmaceutics. 2019; 11: 1-29.

125. Dubashynskaya N, Poshina D, Raik S, Urtti A, Skorik YA. Polysaccharides in ocular drug delivery. Pharmaceutics. 2020; 12: 1-30.

126. $\mathrm{Yu} \mathrm{Y,} \mathrm{Xu} \mathrm{S,} \mathrm{Yu} \mathrm{S,} \mathrm{et} \mathrm{al.} \mathrm{A} \mathrm{Hybrid} \mathrm{Genipin-Cross-Linked} \mathrm{Hydrogel/}$ Nanostructured Lipid Carrier for Ocular Drug Delivery: Cellular, ex vivo, and in vivo Evaluation. ACS Biomater Sci Eng. 2020; 6: 1543-52.

127. Zhai J, Fong C, Tran N, Drummond CJ. Non-Lamellar Lyotropic Liquid Crystalline Lipid Nanoparticles for the Next Generation of Nanomedicine. ACS Nano. 2019; 13: 6178-206.

128. Kanwar R, Rathee J, Salunke DB, Mehta SK. Green nanotechnology-driven drug delivery assemblies. ACS Omega. 2019; 4: 8804-15.

129. Gandara-Loe J, Ortuno-Lizarán I, Fernández-Sanchez L, et al. Metal-Organic Frameworks as Drug Delivery Platforms for Ocular Therapeutics. ACS Appl Mater Interfaces. 2019; 11: 1924-31.

130. Sahoo SK, Labhasetwar V. Nanotech approaches to drug delivery and imaging. Drug Discov Today. 2003; 8: 1112-20.

131. Vasir JK, Labhasetwar V. Targeted drug delivery in cancer therapy. Technol Cancer Res Treat. 2005; 4: 363-74.

132. Labhasetwar V. Nanotechnology for drug and gene therapy: the importance of understanding molecular mechanisms of delivery. Curr Opin Biotechnol. 2005; $16: 674-80$.

133. Jain KK. Nanotechnology-based drug delivery for cancer. Technol Cancer Res Treat. 2005; 4: 407-16.

134. Yih TC, Al-Fandi M. Engineered nanoparticles as precise drug delivery systems. J Cell Biochem. 2006; 97: 1184-90.

135. Juliana FR, Kesse S, Boakye-Yiadom KO, Veroniaina H, Wang H, Sun M. Promising Approach in the Treatment of Glaucoma Using Nanotechnology and Nanomedicine-Based Systems. Molecules. 2019; 24: 3805.

136. Occhiutto ML, Maranhão RC, Costa VP, Konstas AG. Nanotechnology for Medical and Surgical Glaucoma Therapy - A Review. Adv Ther. 2020; 37: 155-99.

137. Kayser O, Lemke A, Hernandez-Trejo N. The impact of nanobiotechnology on the development of new drug delivery systems. Curr Pharm Biotechnol. 2005; 6: $3-5$

138. Brigger I. Dubernet C and Couvreur P. Adv Drug Deliv Rev. 2002; 2002: 54 .

139. Kowluru RA, Zhong Q, Santos JM. Matrix metalloproteinases in diabetic retinopathy: potential role of MMP-9. Expert Opin Investig Drugs. 2012; 21: 797-805.

140. Bhattacharya M, Sarkhel S, Peltoniemi J, et al. Differentially cleaving peptides as a strategy for controlled drug release in human retinal pigment epithelial cells. J Control Release. 2017; 251: 37-48.

141. Abu El-Asrar AM, Ahmad A, Bittoun E, et al. Differential expression and localization of human tissue inhibitors of metalloproteinases in proliferative diabetic retinopathy. Acta Ophthalmol. 2018; 96: e27-37.

142. del Amo EM, Rimpelä A-K, Heikkinen E, et al. Pharmacokinetic aspects of retinal drug delivery. Prog Retin Eye Res. 2017; 57: 134-85.

143. Swindle KE, Hamilton PD, Ravi N. In situ formation of hydrogels as vitreous substitutes: viscoelastic comparison to porcine vitreous. J Biomed Mater Res Part A An Off J Soc Biomater Japanese Soc Biomater Aust Soc Biomater Korean Soc Biomater. 2008; 87: 656-65.

144. Egbu R, Brocchini S, Khaw PT, Awwad S. Antibody loaded collapsible hyaluronic acid hydrogels for intraocular delivery. Eur J Pharm Biopharm. 2018; 124: 95-103.

145. Xie B, Jin L, Luo Z, et al. An injectable thermosensitive polymeric hydrogel for sustained release of Avastin ${ }^{\circledR}$ to treat posterior segment disease. Int J Pharm. 2015; 490: 375-83.

146. Hämäläinen KM, Kananen K, Auriola S, Kontturi K, Urtti A. Characterization of paracellular and aqueous penetration routes in cornea, conjunctiva, and sclera. Invest Ophthalmol Vis Sci. 1997; 38: 627-34.

147. Hosoya K, Lee VHL, Kim K-J. Roles of the conjunctiva in ocular drug delivery: a review of conjunctival transport mechanisms and their regulation. Eur J Pharm Biopharm. 2005; 60: 227-40.
148. Peeters L, Sanders NN, Braeckmans K, et al. Vitreous: a barrier to nonviral ocular gene therapy. Invest Ophthalmol Vis Sci. 2005; 46: 3553-61.

149. Pitkänen L, Ranta V-P, Moilanen H, Urtti A. Permeability of retinal pigment epithelium: effects of permeant molecular weight and lipophilicity. Invest Ophthalmol Vis Sci. 2005; 46: 641-6.

150. Peynshaert K, Fradot V, Picaud S, De Smedt S, Remaut K. Toward rational design of gene carriers: a novel ex vivo model to study the vitreoretinal interface as a barrier. Acta Ophthalmol. 2016; 94

151. Xu Q, Boylan NJ, Suk JS, et al. Nanoparticle diffusion in, and microrheology of, the bovine vitreous ex vivo. J Control release. 2013; 167: 76-84.

152. Li H, Palamoor M, Jablonski MM. Poly (ortho ester) nanoparticles targeted for chronic intraocular diseases: ocular safety and localization after intravitreal injection. Nanotoxicology. 2016; 10: 1152-9.

153. Merodio M, Irache JM, Valamanesh F, Mirshahi M. Ocular disposition and tolerance of ganciclovir-loaded albumin nanoparticles after intravitreal injection in rats. Biomaterials. 2002; 23: 1587-94.

154. Du J, Sun Y, Li F-H, Du L-F, Duan Y-R. Enhanced delivery of biodegradable mPEG-PLGA-PLL nanoparticles loading Cy3-labelled PDGF-BB siRNA by UTMD to rat retina. J Biosci. 2017; 42: 299-309.

155. Chemla Y, Betzer O, Markus A, et al. Gold nanoparticles for multimodal high-resolution imaging of transplanted cells for retinal replacement therapy. Nanomedicine. 2019; 14: 1857-71.

156. Kim JH, Kim MH, Jo DH, Yu YS, Lee TG, Kim JH. The inhibition of retinal neovascularization by gold nanoparticles via suppression of VEGFR-2 activation. Biomaterials. 2011; 32: 1865-71.

157. Jo DH, Kim JH, Son JG, et al. Anti-angiogenic effect of bare titanium dioxide nanoparticles on pathologic neovascularization without unbearable toxicity. Nanomedicine Nanotechnology, Biol Med. 2014; 10: e1109-17.

158. Gurunathan S, Lee K-J, Kalishwaralal K, Sheikpranbabu S, Vaidyanathan R, Eom SH. Antiangiogenic properties of silver nanoparticles. Biomaterials. 2009; 30: 6341-50.

159. Jo DH, Kim JH, Yu YS, Lee TG, Kim JH. Antiangiogenic effect of silicate nanoparticle on retinal neovascularization induced by vascular endothelial growth factor. Nanomedicine Nanotechnology, Biol Med. 2012; 8: 784-91.

160. Rankin TM, Giovinco NA, Cucher DJ, Watts G, Hurwitz B, Armstrong DG. Three-dimensional printing surgical instruments: are we there yet? J Surg Res. 2014; 189: 193-7.

161. Huang W, Zhang X. 3D printing: print the future of ophthalmology. Invest Ophthalmol Vis Sci. 2014; 55: 5380-1.

162. Cohen SR, Gardner TW. Diabetic retinopathy and diabetic macular edema. In: Retinal Pharmacotherapeutics. Karger Publishers; 2016: 137-46.

163. Goswami M, Zhang P, Pugh EN, Zawadzki RJ. Visualization of chorioretinal vasculature in mice in vivo using a combined OCT/SLO imaging system. Ophthalmic Technol XXVI. 2016; 9693: 96930G

164. Group DRSR. Photocoagulation treatment of proliferative diabetic retinopathy: the second report of diabetic retinopathy study findings. Ophthalmology. 1978; 85: 82-106.

165. Blumenkranz MS, Yellachich D, Andersen DE, et al. Semiautomated patterned scanning laser for retinal photocoagulation. Retina. 2006; 26: 370-6.

166. Vujosevic S, Martini F, Convento E, et al. Subthreshold laser therapy for diabetic macular edema: metabolic and safety issues. Curr Med Chem. 2013; 20: 3267-71.

167. Neubauer AS, Langer J, Liegl R, et al. Navigated macular laser decreases retreatment rate for diabetic macular edema: a comparison with conventional macular laser. Clin Ophthalmol (Auckland, NZ). 2013; 7: 121.

168. Massin P, Bandello F, Garweg JG, et al. Safety and efficacy of ranibizumab in diabetic macular edema (RESOLVE Study): a 12-month, randomized, controlled, double-masked, multicenter phase II study. Diabetes Care. 2010; 33. $2399-405$

169. Mitchell P, Bandello F, Schmidt-Erfurth U, et al. The RESTORE study: ranibizumab monotherapy or combined with laser versus laser monotherapy for diabetic macular edema. Ophthalmology. 2011; 118: 615-25.

170. Wells JA, Glassman AR, Ayala AR, et al. Aflibercept, bevacizumab, or ranibizumab for diabetic macular edema. N Engl J Med. 2015; 372: 1193-203.

171. Sultan MB, Zhou D, Loftus J, Dombi T, Ice KS, Group M 1013 S. A phase 2/3, multicenter, randomized, double-masked, 2-year trial of pegaptanib sodium for the treatment of diabetic macular edema. Ophthalmology. 2011; 118: 1107-18.

172. Wroblewski JJ, Hu AY. Topical squalamine $0.2 \%$ and intravitreal ranibizumab $0.5 \mathrm{mg}$ as combination therapy for macular edema due to branch and central retinal vein occlusion: An open-label, randomized study. Ophthalmic Surgery, Lasers Imaging Retin. 2016; 47: 914-23.

173. Campochiaro PA, Khanani A, Singer M, et al. Enhanced benefit in diabetic macular edema from AKB-9778 Tie2 activation combined with vascular endothelial growth factor suppression. Ophthalmology. 2016; 123: 1722-30.

174. Boyer DS, Yoon $\mathrm{YH}$, Belfort $\mathrm{Jr} \mathrm{R}$, et al. Three-year, randomized, sham-controlled trial of dexamethasone intravitreal implant in patients with diabetic macular edema. Ophthalmology. 2014; 121: 1904-14.

175. Pacella F, Romano MR, Turchetti P, et al. An eighteen-month follow-up study on the effects of Intravitreal Dexamethasone Implant in diabetic macular edema refractory to anti-VEGF therapy. Int J Ophthalmol. 2016; 9: 1427.

176. Campochiaro PA, Brown DM, Pearson A, et al. Long-term benefit of sustained-delivery fluocinolone acetonide vitreous inserts for diabetic macular edema. Ophthalmology. 2011; 118: 626-35. 
177. Augusti KT. Effect of alloxan diabetes of allyl propyl disulphide obtained from onion. Naturwissenschaften. 1974; 61: 172.

178. Jain RC, Vyas CR, Mahatma OP. Hypoglycaemic action of onion and garlic. Lancet. 1973; 302: 1491

179. Khan AK, Akhtar S, Mahtab H. Treatment of diabetes mellitus with Coccinia indica. Br Med J. 1980; 280: 1044.

180. Pillai NR, Seshadri C, Santhakumari G. Hypoglycaemic effect of Cyamopsis tetragonoloba taub (gowar). Indian J Med Res. 1980; 72: 128-31.

181. Brahmachari HD. ISOLATION OF ORALLY EFFECTIVE HYPOGLYCEMIC COMPOU DS FROM FICUS BENGALENSIS LI'. 1964.

182. Leatherdale BA, Panesar RK, Singh G, Atkins TW, Bailey CJ, Bignell AH. Improvement in glucose tolerance due to Momordica charantia (karela). Br Med J (Clin Res Ed). 1981; 282: 1823-4.

183. Meir P, Yaniv Z. An in vitro study on the effect of Momordica charantia on glucose uptake and glucose metabolism in rats. Planta Med. 1985; 51: 12-6.

184. Akhtar MS. Trial of Momordica charantia Linn (Karela) powder in patients with maturity-onset diabetes. J Pak Med Assoc. 1982; 32: 106-7.

185. Mishkinsky JS, Goldschmied A, Joseph B, Ahronson Z, Sulman FG. Hypoglycaemic effect of Trigonella foenum graecum and Lupinus termis (leguminosae) seeds and their major alkaloids in alloxan-diabetic and normal rats. Arch Int Pharmacodyn thérapie. 1974; 210: 27-37.

186. Manna S, Banerjee RK, Augsburger JJ, Al-Rjoub MF, Donnell A, Correa ZM. Biodegradable chitosan and polylactic acid-based intraocular micro-implant for sustained release of methotrexate into vitreous: analysis of pharmacokinetics and toxicity in rabbit eyes. Graefe's Arch Clin Exp Ophthalmol. 2015; 253: 1297-305.

187. Jaffe GJ, Yang CH, Guo H, Denny JP, Lima C, Ashton P. Safety and pharmacokinetics of an intraocular fluocinolone acetonide sustained delivery device. Invest Ophthalmol Vis Sci. 2000; 41: 3569-75.

188. Smith TJ, Pearson PA, Blandford DL, et al. Intravitreal sustained-release ganciclovir. Arch Ophthalmol. 1992; 110: 255-8.

189. Kane FE, Green KE. Ocular pharmacokinetics of fluocinolone acetonide following Iluvien implantation in the vitreous humor of rabbits. J Ocul Pharmacol Ther. 2015; 31: 11-6.

190. Chang-Lin J-E, Attar M, Acheampong AA, et al. Pharmacokinetics and pharmacodynamics of a sustained-release dexamethasone intravitreal implant. Invest Ophthalmol Vis Sci. 2011; 52: 80-6.

191. Bhagat R, Zhang J, Farooq S, Li X-Y. Comparison of the release profile and pharmacokinetics of intact and fragmented dexamethasone intravitreal implants in rabbit eyes. J Ocul Pharmacol Ther. 2014; 30: 854-8.

192. Zhang L, Shen W, Luan J, et al. Sustained intravitreal delivery of dexamethasone using an injectable and biodegradable thermogel. Acta Biomater. 2015; 23: 271-81.

193. Awwad S, Day RM, Khaw PT, Brocchini S, Fadda HM. Sustained release ophthalmic dexamethasone: in vitro in vivo correlations derived from the PK-eye. Int J Pharm. 2017; 522: 119-27.

194. Pan CK, Durairaj C, Kompella UB, et al. Comparison of long-acting bevacizumab formulations in the treatment of choroidal neovascularization in a rat model. J Ocul Pharmacol Ther. 2011; 27: 219-24. 